\title{
Assessment of Low Cost Novel Sorbents for Coal-Fired Power Plant Mercury Control
}

\section{Final Report}

\author{
Reporting Period Start: August 2, 2001 \\ Reporting Period End: March 31, 2004
}

Prepared by:

Apogee Scientific, Inc.

Report Issue Date: March 2004

DOE Award Number: DE-FC26-01NT41180

\begin{abstract}
Apogee Scientific, Inc.
2895 West Oxford Ave, Suite 1

Englewood, CO 80110-4397

(303) 783-9599

URS Group, Inc.

9400 Amberglen Blvd

Austin, TX 78729

Electric Power Research Institute

3412 Hillview Ave.

Palo Alto, CA 94304-1395

Illinois State Geological Survey

615 East Peabody Drive

Champaign, IL 61820-6964
\end{abstract}

\author{
ADA-ES, LLC \\ 8100 South Park Way, Unit B \\ Littleton, CO 80120
}




\section{Disclaimer}

"This report was prepared as an account of work sponsored by an agency of the United States Government. Neither the United States Government nor any agency thereof, nor any of their employees, makes any warranty, express or implied, or assumes any legal liability or responsibility for the accuracy, completeness, or usefulness of any information, apparatus, product, or process disclosed, or represents that its use would not infringe privately owned rights. Reference herein to any specific commercial product, process, or service by trade name, trademark, manufacturer, or otherwise does not necessarily constitute or imply its endorsement, recommendation, or favoring by the United States Government or any agency thereof. The views and opinions of authors expressed herein do not necessarily state or reflect those of the United States Government or any agency thereof." 


\section{Acknowledgements}

This project was successful only with the help and guidance by numerous entities.

Special thanks to the host facilities and personnel: We Energies' Valley Power Plant and Pleasant Prairie Power Plant and Midwest Generation's Powerton Station. The Electric Power Research Institute (EPRI), Illinois Corn Marketing Board, Illinois State Geological Survey (ISGS), Williams Bio Energy, and the above-mentioned host facilities provided in-kind cost share. Team members on this project include the URS Group, EPRI, ISGS, and ADA-ES. Sorbents evaluated on this project were provided at no cost by numerous vendors. 


\begin{abstract}
The injection of sorbents upstream of a particulate control device is one of the most promising methods for controlling mercury emissions from coal-fired utility boilers with electrostatic precipitators and fabric filters. Studies carried out at the bench-, pilot-, and full-scale have shown that a wide variety of factors may influence sorbent mercury removal effectiveness. These factors include mercury species, flue gas composition, process conditions, existing pollution control equipment design, and sorbent characteristics.

The objective of the program is to obtain the necessary information to assess the viability of lower cost alternatives to commercially available activated carbon for mercury control in coal-fired utilities. Prior to injection testing, a number of sorbents were tested in a slipstream fixed-bed device both in the laboratory and at two field sites. Based upon the performance of the sorbents in a fixed-bed device and the estimated cost of mercury control using each sorbent, seventeen sorbents were chosen for screening in a slipstream injection system at a site burning a Western bituminous coal/petcoke blend, five were chosen for screening at a site burning a subbituminous Powder River Basin (PRB) coal, and nineteen sorbents were evaluated at a third site burning a PRB coal. Sorbents evaluated during the program were of various materials, including: activated carbons, treated carbons, other non-activated carbons, and non-carbon material.
\end{abstract}

The economics and performance of the novel sorbents evaluated demonstrate that there are alternatives to the commercial standard. Smaller enterprises may have the opportunity to provide lower price mercury sorbents to power generation customers under the right set of circumstances. 


\section{Table of Contents}

1.0 Introduction ...................................................................................................................................................... 1

2.0 Executive Summary................................................................................................................................... 3

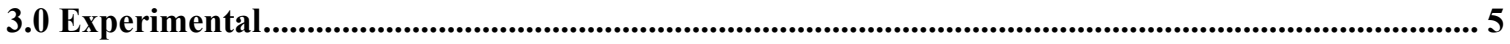

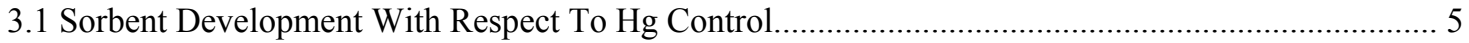

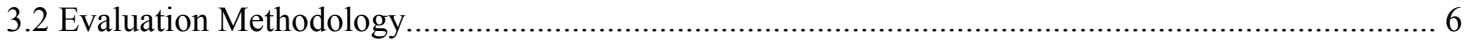

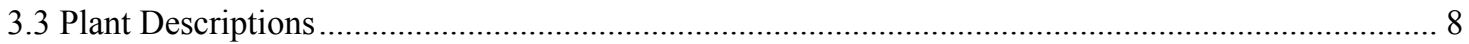

3.3.1 Midwest Generation's Powerton Station.................................................................. 8

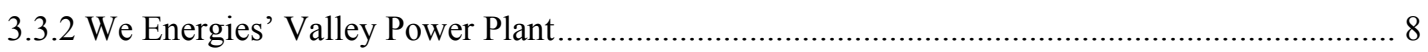

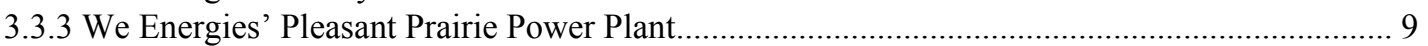

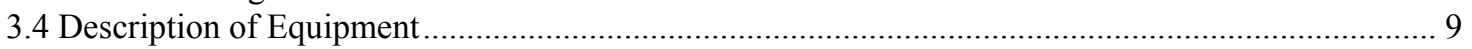

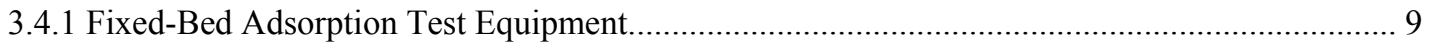

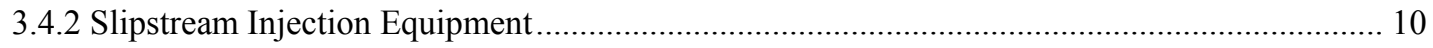

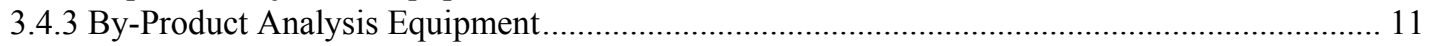

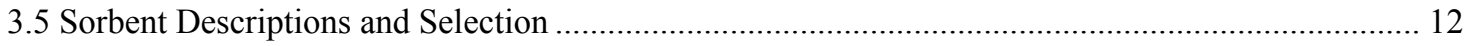

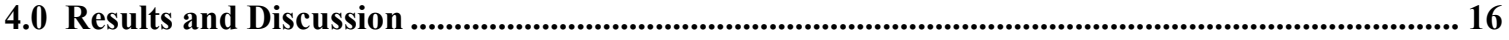

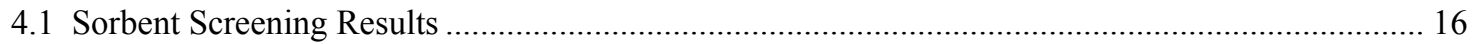

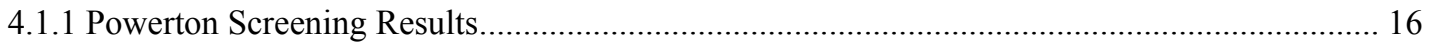

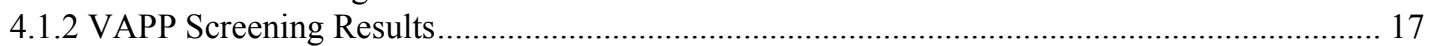

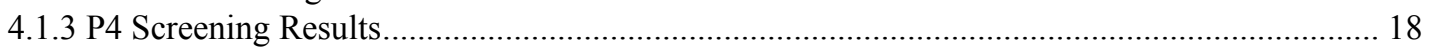

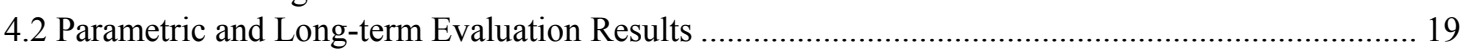

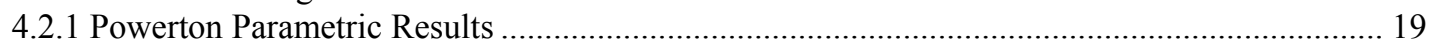

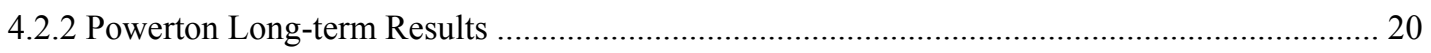

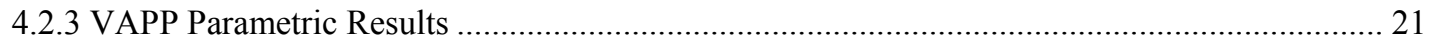

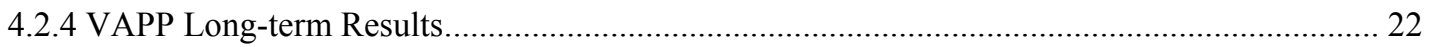

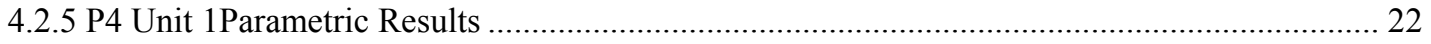

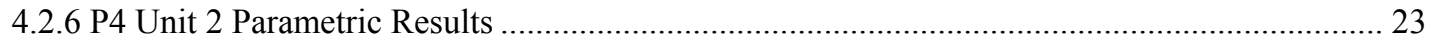

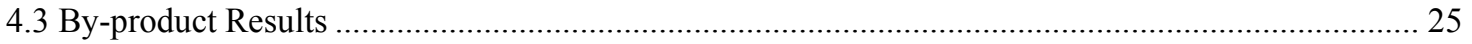

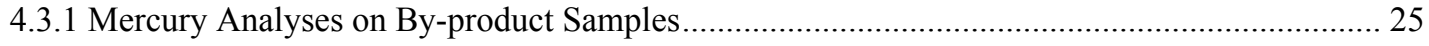

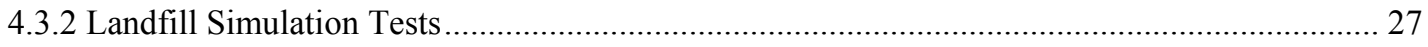

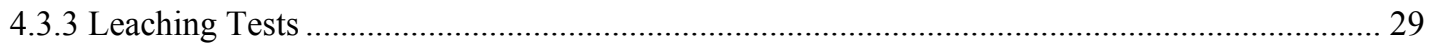

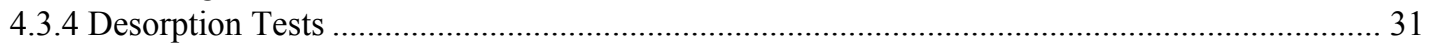

5.0 Economic Analyses ................................................................................................................................... 32

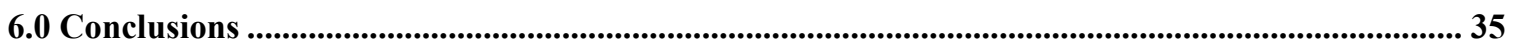

Appendix A. Description of Mercury Monitors and Sampling Procedures ............................................... 37

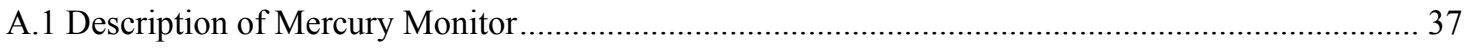

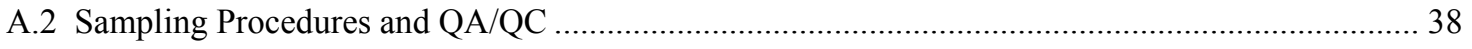

A.3 Bench Scale Fixed Bed Adsorption Test Device ……...................................................................... 39

Appendix B. By-Product Equipment and Procedures .................................................................................. 41

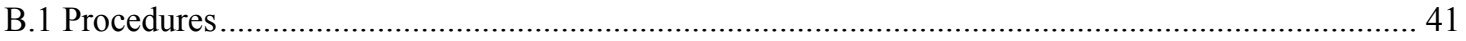

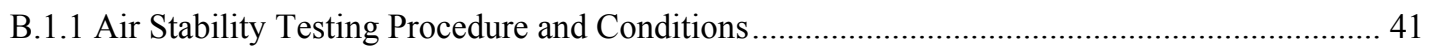

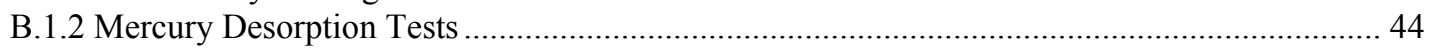

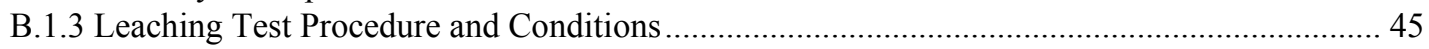






Appendix D. Laboratory Sorbent Fixed-Bed Evaluations ........................................................4

References 


\section{Figures}

Figure 1. PoCT Residence Time Chamber. .............................................................. 10

Figure 2. PoCT configured for TOXECON evaluations. ............................................ 11

Figure 3. Results from sorbent screening at Powerton. Injection concentration $\sim 1.5$ lb/Mmacf.

Figure 4. Results from sorbent screening at VAPP at an injection concentration $\sim 2.0$ lb/Mmacf.

Figure 5. Results from sorbent screening on P4's Unit 1. Batch injection concentration equivalent to $1 \mathrm{lb} / \mathrm{Mmacf}$ for 1 hour.

Figure 6. Comparison of mercury removal at $300^{\circ} \mathrm{F}$ and $350^{\circ} \mathrm{F}$ at Powerton.

Figure 7. Comparison of mercury removal for sorbents at VAPP at $315^{\circ} \mathrm{F}$ and $350^{\circ} \mathrm{F} \ldots 22$

Figure 8. Mercury sorbent parametric evaluations on Unit 1 at P4.

Figure 9. Parametric sorbent evaluations on P4's Unit 2 with and without SCR on line at a gas temperature of $300^{\circ} \mathrm{F}$. Repeated data shown where available for individual sorbents.

Figure 10. Parametric sorbent evaluations on P4's Unit 2 with SCR on line at a gas temperature of $300^{\circ} \mathrm{F}$.

Figure 11. Parametric sorbent evaluations on P4's Unit 2 with SCR on line at two gas temperatures. Repeated data shown where available for individual sorbents. 25

Figure 12. Sorbent comparison for mercury removal at the three test sites. 35

Figure A-1. Sketch of mercury measurement system........................................... 37

Figure A-2. Photograph of Apogee mercury S-CEM installed at a field site................. 38

Figure A-3. Bench Scale Fixed Bed Adsorption Test Device. .................................... 40

Figure B- 1. Schematic of the Landfill Simulation Test Set Up................................. 41

Figure B-2. Photograph of the Room Temperature Landfill Test Set Up. ..................... 43

Figure B-3. Photograph of the $140^{\circ} \mathrm{F}$ Landfill Test Set Up....................................... 43 


\section{Tables}

Table 1. Sorbent Equilibrium Adsorption Capacity Measured in the Laboratory and at Powerton.

Table 2. Sorbent Equilibrium Adsorption Capacity Measured in the Laboratory and at VAPP.

Table 3. Descriptions of Sorbents Evaluated at Powerton............................................... 14

Table 4. Descriptions of Sorbents Evaluated at VAPP................................................ 15

Table 5. Descriptions of Sorbents Evaluated at P4 ................................................... 15

Table 6. Powerton By-product Sample Mercury Concentration and LOI Data Summary.

Table 7. VAPP By-product Sample Mercury Concentration and LOI Data Summary.... 26

Table 8. Results of Powerton Room Temperature Landfill Simulation Tests.................. 27

Table 9. Results of Powerton $140^{\circ} \mathrm{F}$ Landfill Simulation Tests. ...................................... 28

Table 10. Results of VAPP Room Temperature Landfill Simulation Tests..................... 28

Table 11. Results of VAPP $140^{\circ} \mathrm{F}$ Landfill Simulation Tests. .......................................... 29

Table 12. Leaching Results of the Powerton By-product Samples in SPLP Matrix and

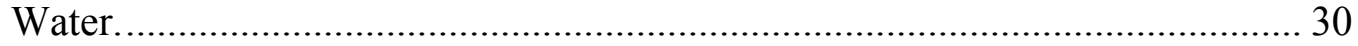

Table 13. Leaching Results of the VAPP By-product Sample in SPLP Matrix, Water,

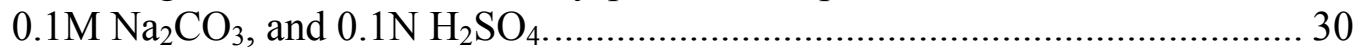

Table 14. Powerton By-product Samples Desorption Profile............................................ 31

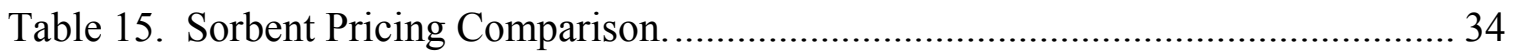

Table B-1. Landfill Simulation Carulite Change Schedule ( \pm 1 week) ............................ 42

Table D-1. Results from Laboratory Fixed-Bed Mercury Adsorption Capacity Tests on Simulated Low Sulfur Eastern Bituminous Flue Gas. .......................................... 47

Table D-2. Results from Laboratory Fixed-Bed Mercury Adsorption Capacity Tests on

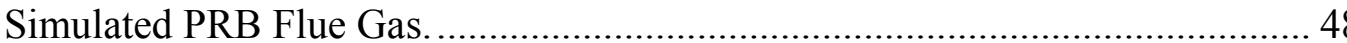




\subsection{Introduction}

On December 15, 2003, the Unites States Environmental Protection Agency (EPA) announced two options for a proposed rule to reduce the current mercury $(\mathrm{Hg})$ emissions from coal-fired power plants in the Unites States. The first is a two-phase market-based cap-and-trade approach that assumes "co-benefits" reductions of mercury emissions in 2010, and a cap of 15 tons (13.5 metric tons) after 2018, a reduction of $70 \%$ from current levels. The second is a maximum achievable control technology (MACT) approach that establishes separate emission limits for mercury for new and existing coal-fired electric utility steam generating units, respectively, with compliance expected by December 2007. EPA estimates that the section 112 MACT proposal will reduce national $\mathrm{Hg}$ emissions to approximately 34 tons (30.6 metric tons). EPA will promulgate a final rule by December 2004.

With the proposed rules, the mercury emissions will be reduced by 14 tons (12.5 metric tons) by the end of 2007, or by 33 tons ( 29.5 metric tons) by 2018 depending on the final ruling option. Details of the proposals are given in the Federal Register. Under these proposed rules, some power plants may not need additional mercury controls beyond baseline (MACT floors for specific coal categories are different. For existing units, emissions limit are 2.0, 5.8, and 9.2 lb/Tbtu $(0.96,2.8$, and $4.4 \mu \mathrm{g} / \mathrm{J})$ for bituminous, subbituminous, and lignites, respectively). Others may opt to look at high removals for cap and trade. More stringent rules can still result from individual states, which may opt for

greater control levels. At this stage, the determination of cost effective control strategies becomes more complex and requires power plants to assess a number of control options that range from low to high mercury removal effectiveness.

Injection of activated carbon upstream of either an electrostatic precipitator (ESP) or a fabric filter baghouse is the retrofit technology that has the widest potential application for controlling mercury emissions in plants that are not equipped with flue gas desulfurization (FGD-s) scrubbers, which includes $75 \%$ of all U.S. plants (1). However, sorbent costs represent a large fraction of the overall costs, especially for units equipped with ESPs. In order to make sorbent injection (for mercury removal) more cost effective, it is necessary to either reduce the amount of sorbent needed or decrease the cost of sorbent production.

This program is funded by the Department of Energy's National Energy Technology Laboratory (NETL) to obtain the necessary information to assess the viability of lower cost alternatives to commercially available activated carbon for mercury control in coalfired utilities. Sorbent evaluations were conducted by Apogee Scientific, Inc. (Apogee) from June 2002 to January 2004 at three coal-fired utilities. Injection testing was conducted using the Electric Power Research Institute's multi-Pollution Control Test (PoCT) system configured either as a COHPAC baghouse, or a residence-time chamber (which simulates the mercury removal in the first field of an ESP). Mercury removal across the slipstream injection device was measured with and without sorbent injection. 
The three field sites chosen were: Midwest Generation's Powerton Station (Powerton) burning a PRB subbituminous coal, We Energies' Valley Power Plant (VAPP) burning a blend of Western bituminous coal and petcoke, and We Energies' Pleasant Prairie Power Plant (P4) also burning a PRB coal.

Five novel sorbents were evaluated with the slipstream PoCT system at Powerton, seventeen sorbents at VAPP, and nineteen sorbents at P4. Selection criteria for the Powerton and VAPP studies were based upon the performance of the sorbents in laboratory fixed bed evaluations and the estimated cost of mercury control using each sorbent with projected costs of $25 \%$ less than commercially available Norit Americas' Darco FGD ${ }^{\mathrm{TM}}$ carbon (FGD), which was the baseline sorbent for this project. The P4 evaluations were added at the end of the program and the sorbents selected for testing were based on projected costs being 25\% less than FGD carbon. This report presents data collected during these field evaluations, which will provide information to determine costs and capabilities of these novel sorbents for plants burning similar coals. 


\subsection{Executive Summary}

On December $15^{\text {th }} 2003$, EPA announced that it would regulate mercury emissions from coal-fired boilers by either using a "cap and trade" approach or a maximum achievable control technology (MACT) standard. Sorbent injection (injection of sorbent upstream of a particulate control system) is one of the more promising options for power plant flue gas mercury control. During most of the testing to-date, a commercially available activated carbon from Norit Americas, Darco FGD ${ }^{\mathrm{TM}}$ (FGD), was used as the injected sorbent which to-date has limited the option costs for this control application.

This program was funded by the Department of Energy's National Energy Technology Laboratory (NETL) to obtain the necessary information to assess the viability of lower cost alternatives to commercially available activated carbon for mercury control in coalfired utilities. Sorbents that had a projected cost savings of at least $25 \%$ compared to the current commercial price of the benchmark sorbent, FGD were chosen for this program. This projected cost includes cost for producing the sorbent, transportation, handling, feeding, balance-of-plant impacts, and waste handling costs. This report is a summary of injection testing conducted at three test sites, Midwest Generation's Powerton Station (Powerton), We Energies' Valley Power Plant (VAPP), and We Energies' Pleasant Prairie Power Plant (P4). The injection tests used the Electric Power Research Institute's multi-Pollution Control Test (PoCT) system configured as a COHPAC baghouse, or a residence-time chamber (which simulates the mercury removal in the first field of an electrostatic precipitator).

The objective of tests conducted during this program was to compare low cost novel sorbents for mercury removal by assessing the effect of sorbent injection on vapor-phase mercury control at the three test sites. Apogee Scientific, Inc. (Apogee) conducted sorbent evaluations from June 2002 to January 2004 at the three coal-fired utilities. Five novel sorbents were evaluated with the slipstream PoCT system at Powerton, seventeen sorbents at VAPP, and nineteen sorbents at P4. Evaluated sorbents are of various materials, including: activated carbons, treated carbons, other carbons, and non-carbon materials. FGD was tested as the benchmark sorbent at all three sites.

The best performing sorbents were carbon-based as demonstrated at the three field locations. Performance of the carbon-based sorbents varied and the mercury removal could not be correlated to the amount of modification (i.e. activation or treatment) performed on the base sorbent. Specialty carbons, such as iodated activated carbon (IAC), were included in the program since they have demonstrated enhanced performance at certain plant sites. Their performance (lower injection concentrations required in some cases) may offset the higher up front cost (currently $\sim \$ 7 / \mathrm{lb}$ delivered for IAC), which may provide an economic advantage with specific coals and plant operations. Please note the results for the IAC screening were at injection concentrations much less than that of the other sorbents during screening. For the IAC tests, the injection concentrations were $0.6,1.7$, and $0.5 \mathrm{lb} / \mathrm{Mmacf}$ for Powerton, VAPP, and P4, respectively. 
Non carbon-based sorbents although not as effective as the carbon-based sorbents tested, may have an economic benefit where by-product resale/utilization is an economic consideration. This program did not attempt to validate claims by the sorbent suppliers as to their impact on fly ash reuse. Performance of the sorbents grouped in the "other" category varied depending on the base material (flyash, zeolite, other). The zeolite-based sorbents performed better than the fly ash-based sorbents during sorbent screening at VAPP and P4. Both the Thief and AMS sorbents removed greater than $60 \%$ of the incoming mercury in the TOXECON configuration at $\mathrm{P} 4$.

Temperature of the flue gas did not significantly affect sorbent performance in the COHPAC or residence chamber configurations at Powerton. At VAPP, mercury removal increased slightly at the higher temperature $\left(315^{\circ} \mathrm{F}\right.$ to $\left.350^{\circ} \mathrm{F}\right)$ for all three sorbents evaluated in the COHPAC configuration but not in the residence chamber configuration. In addition, sorbent performance increased with increased residence time and injection concentration at both VAPP and Powerton. At P4, the impact of increasing the temperature from $280^{\circ} \mathrm{F}$ to $350^{\circ} \mathrm{F}$ decreased the mercury removal performance for all sorbents evaluated. The greatest difference was seen at the lower injection rates. Other plant characteristics may influence sorbent performance and the effect of temperature had on sorbent performance may not be universal to all plants burning similar coals as demonstrated in this program.

Re-injection of sorbent/by-product was evaluated at Powerton using the HOK sorbent and demonstrated 53\% mercury removal compared to $83 \%$ mercury removal with fresh sorbent. Depending on the plant conditions, costs, and mercury removal required, this concept could be an option for reducing mercury sorbent injection control costs.

Results of the by-product analysis demonstrated that no mercury was released during the air stability or leaching evaluations.

Sorbent economics will be driven by the supply and demand of effective sorbents. If there are viable resources located within close proximity of coal-fired utilities, then lower cost options may be available on a case by case basis. Price of the sorbent will also depend on the required mercury reduction needed by the individual utilities. With the information presented on the control of mercury using sorbents for the two coal types of Western bituminous and PRB evaluated during this project, there are a wide range of sorbents that could be made available to satify utilities that require $30 \%$ to $70 \%$ mercury removal when using a similar particulate control scenerio. Other plant issues also need to be addressed when considering sorbent injection with the impact on the sale of byproducts being at the top of the list. The sorbent's overall economic impact needs to be taken into account when considering the control technology and cost of mercury control. Again, the overall cost of the sorbents evaluated during this program were not independly verified. Although larger companies with more marketing infrastructure, reliability, and negotiating power will supply a large share of the sorbent market, smaller enterprises certainly have the opportunity to provide a lower price to their customers under the right set of circumstances. 


\subsection{Experimental}

\subsection{Sorbent Development With Respect To Hg Control}

Several factors potentially affect the ability of a sorbent to remove mercury from flue gas. These include the mercury species being removed (oxidized vs. elemental), the flue gas composition, process conditions (e.g., gas temperature), sorbent characteristics, and the presence of other active surfaces (e.g., fly ash or calcium sorbents added to remove acid gases). In coal-fired flue gas, vapor-phase mercury is present both as oxidized mercury and elemental mercury $\left(\mathrm{Hg}^{0}\right)$. Oxidized mercury is generally assumed to be present as mercuric chloride $\left(\mathrm{HgCl}_{2}\right)$, although mercuric oxides or sulfates may form in the presence of active surfaces. The chemical form of mercury potentially affects sorbent performance. Concentrations of other gas components, such as sulfur oxides, nitrogen oxides, chlorine compounds, and water, also affect mercury adsorption. These variables can affect the application of sorbent injection for mercury control since the flue gas composition can vary widely from one boiler to another.

While the above factors influence mercury adsorption and removal, the most important factors are probably the sorbent type and its associated properties. Research by the Electric Power Research Institute (EPRI) and others have been conducted to identify the various properties that enable a given sorbent to effectively adsorb mercury.

Additionally, variations in physical properties such as size, shape, effective surface area, and porosity, also may affect sorbent adsorption performance (1).

Research to date has demonstrated that mercury adsorption decreases as the reaction temperature increases or as the bulk mercury concentration in the flue gas decreases (2). These results are evidence of an underlying physical adsorption mechanism.

Flue gas composition significantly affects mercury adsorption to sorbent surfaces. Higher concentrations of $\mathrm{SO}_{2}$ or $\mathrm{NO}_{\mathrm{x}}$ typically hinder mercury adsorption by activated carbons while increasing the $\mathrm{HCl}$ concentration enhances adsorption. The presence of $\mathrm{NO}_{\mathrm{x}}$ in the flue gas decreases the individual effects of $\mathrm{SO}_{2}, \mathrm{HCl}$, and temperature. The observed effects of flue gas composition suggest that the mercury adsorption mechanisms are not entirely physical in nature. Most carbon-based sorbents appear to be affected by flue gas composition in similar ways. However, other material-based sorbents may be affected differently indicating different adsorption mechanisms.

Field and laboratory evaluations with experimental activated carbons have identified the sorbent properties that influence mercury adsorption $(1,3,4)$. These include surface area, pore size distribution, and pore volume distribution. Mercury adsorption by some activated carbons showed a direct correlation to specific surface area, micropore volume, and mesopore volume. However, these correlations only held for carbons derived from high-sulfur coals.

The surface functional groups of a sorbent, especially sulfur species, can strongly affect mercury adsorption. Organic sulfur species enhance mercury adsorption much more than inorganic sulfur species. Doping carbon sorbents with sulfur can enhance capacities for 
$\mathrm{Hg}^{0}$ and $\mathrm{HgCl}_{2}$ when organic sulfur is not present in the raw sorbent. However, the temperature and process used to impregnate the sorbent determines which sulfur functional groups will form and, therefore, the extent of adsorption enhancement (1).

Further studies have identified various waste biomass materials as good sources for producing activated carbons that are highly effective for mercury adsorption. Waste tires could be another good source (4). Since biomass does not need pretreatment and can be carbonized in one step, the cost for carbon production should be relatively low compared to commercial activated carbon. In addition, local biomass sources can be customized for use at neighboring utilities, hence possibly reducing the transportation and overall costs of mercury control.

Laboratory and pilot-scale tests have indicated fly ashes can also adsorb mercury. In general, fly ash adsorbs substantially less mercury than activated carbon at similar conditions. Also, fly ash is generally unable to achieve total mercury adsorption but, rather, adsorbs only a fraction from the gas. However, when considering the high concentration of ash present in flue gas, it is conceivable that, even with relatively low capacities, the ash may be able to remove substantial amounts of mercury from the gas. Previous tests indicated that mercury removal by fly ashes was affected by flue gas composition in a similar manner as activated carbons. Results also suggest that for a given fly ash, the fly ash mercury capacities correlate with the concentration of unburned carbon in the ash. Recent results also indicate that mercury capacity of a fly ash can be increased by a simple chemical activation (4).

Other novel sorbents produced and tested in EPRI programs include various zeolites (4). Zeolites may have less impact on fly ash use since they are basically silica-alumina based material.

Bench-scale fixed-bed adsorption tests have provided a better understanding of the factors that affect mercury adsorption and provide a relative indication of performance for different sorbents. However, the ability of a given sorbent to remove mercury in fullscale systems cannot be predicted based on the laboratory results alone. To predict mercury removal in full-scale systems, EPRI has developed a mathematical model that couples the results obtained in laboratory tests with mass transfer considerations $(5,6)$. The model incorporates characteristics related to the sorbent (e.g., affinity for mercury, specific surface area, and particle size), mass transfer within a given system, total surface area available for adsorption, and duct residence time. The model has been used to determine conditions under which either mass transfer limitations or sorbent capacities control the extent of mercury removal when injecting sorbents into the duct upstream of an environmental control device such as an ESP or fabric filter baghouse. A detailed description of the model as well as predicted results is provided elsewhere $(5,6)$.

\subsection{Evaluation Methodology}

For this program, evaluating sorbent injection for mercury control began with a series of laboratory and field tests designed to evaluate mercury removal in flue gas specific to the sites tested. To be considered for laboratory evaluation during this program, the sorbent 
manufacturer was required to provide evidence that the cost for removing mercury (per pound of mercury removed) will be at least 25\% less that that of FGD. This cost includes not only the cost for producing the carbon but transportation, handling, feeding, and waste handling costs that may differ from FGD. In addition, sufficient quantities of the sorbent would need to be available to supply at least 100,000 tons per year to the utility market by 2010 .

Once the sorbent manufacturer determined cost and availability, the mercury performance potential was characterized. In order to evaluate the potential of any mercury sorbent and model it's performance, the equilibrium adsorption capacity and characteristics of the sorbent must be known. Scientists at the URS Group conducted fixed-bed adsorption (breakthrough) tests to generate sorbent equilibrium data for each of the candidate novel sorbents considered for evaluations at Powerton and VAPP.

Sorbents were screened by measuring their capacity in the laboratory using simulated low-sulfur eastern bituminous or PRB flue gas prior to field-testing in the actual host flue gas. The purpose of these laboratory tests was to evaluate a number of sorbents at conditions similar to those expected at Powerton (27 sorbents) and VAPP (47 sorbents). The test results were used to determine the most appropriate sorbents for the field evaluations. A control sample, Norit America's FGD ${ }^{\mathrm{TM}}$ carbon, was used as the benchmark sorbent for this program.

Following laboratory testing, small-scale fixed-bed screening tests on selected sorbents were performed at Powerton (8 sorbents) and VAPP (17 sorbents) using EPRI's mini sorbent test system. The results of these tests were used to determine which samples to test in a series of small-scale slipstream injection tests using EPRI's PoCT system. The test units and respective methods used are described later in this report. For VAPP, some mercury sorbents were later added to the slipstream screening process without going through the laboratory or field fixed-bed screening because of more recent developments in sorbent technology since the start of the program. Sorbents evaluated at P4 were not evaluated in a fixed-bed arrangement because this site was added to the program at a later time.

During slipstream injection evaluations, two particulate-control configurations were tested to assess mercury removal using sorbent injection upstream of a COHPAC baghouse and upstream of an ESP. A COHPAC module designed for sorbent injection is also called TOXECON. In the TOXECON configuration three sets of tests were conducted at both VAPP and Powerton. Sorbent evaluations were as follows:

1. Sorbent Screening. Each available sorbent was injected for about 20 minutes at Powerton $\left(300^{\circ} \mathrm{F}\right)$ and 120 minutes at VAPP $\left(315^{\circ} \mathrm{F}\right)$ utilizing a continuous injection.

2. Parametric Evaluations. The two most-promising sorbents from screening and economic criteria considerations were tested at various continuous injection rates and two gas temperatures. Each test condition was held constant for approximately 1.5 hours at Powerton and 4 hours at VAPP. 
3. Long-term Evaluations. The two most-promising sorbents were tested continuously for 8-12 hours at Powerton and 48 hours at VAPP. The collected solids from the baghouse hoppers were retained for by-product characterization evaluations.

Sorbent injection screening at $\mathrm{P} 4$ was conducted at a single batch injection rate (equivalent to $1 \mathrm{lb} / \mathrm{Mmacf}$ for 1 hour) and a gas temperature $\left(300^{\circ} \mathrm{F}\right)$ using the PoCT system configured as a COHPAC baghouse. The batch injection rate was equivalent to 1.09 grams of sorbent batch injected into the system at two equal quantities ( 0.545 grams) four minutes apart. Parametric evaluations also utilized batch injections at various injection rates and two gas temperatures.

In the residence chamber configuration (performed at VAPP and Powerton), two selected novel sorbents and FGD were parametrically tested for 60-90 minutes each, with the variables being gas temperature, injection rate, and residence time ( 2 and 4 seconds).

\subsection{Plant Descriptions}

\subsubsection{Midwest Generation's Powerton Station}

The first field site was Midwest Generation's Powerton Generating Station, Unit 5. Slipstream evaluations with the PoCT system began June 12, 2002 and continued until July 17, 2002. Midwest Generation is a subsidiary of Edison Mission Energy and is part of the Edison International family of companies.

The Powerton Unit 5 and Unit 6 boilers are identical B\&W cyclone boilers burning pulverized subbituminous coal from the Powder River Basin. Both boilers (nominally $450 \mathrm{MW}$ each) are used to power one turbine, rated at $893 \mathrm{MW}$. A Research Cottrell electrostatic precipitator with a weighted wire design controls particulate emissions. The nominal specific collection area of the precipitators are 217 and $424 \mathrm{ft}^{2} / \mathrm{kacfm}$.

Based on 1999 EPA Information Collection Request (ICR) coal data (7), the PRB coal at this site has $20 \mathrm{ppm}$ to $250 \mathrm{ppm}$ chlorine, 0.06 to $0.3 \mu \mathrm{g} / \mathrm{g}$ mercury, and $0.4 \%$ sulfur. This site is also located adjacent to the Williams Bio-Energy facility that provided one of the biomass-material sorbents evaluated in this project.

\subsubsection{We Energies' Valley Power Plant}

The second field site was We Energies' Valley Power Plant, Boiler 3. Evaluations began January 22, 2003 at VAPP and were completed April 15, 2003.

VAPP is a cogeneration facility producing steam for the City of Milwaukee and electricity. The boiler is a Riley Stoker front wall-fired, balanced draft boiler burning a mix of pulverized Western bituminous coal (85\%) and petroleum coke $(15 \%)$. The boiler is rated at 650,000 pounds of steam per hour. Riley Stoker Model CCV Low NOx burners are installed in the boiler. An Environmental Elements pulse-jet fabric filter baghouse is used to control particulate emissions. 
Based upon coal data provided to EPA during the ICR effort (7), the mercury level in the coal in 1999 varied from 0.011 to $0.11 \mu \mathrm{g} / \mathrm{g}, 50$ to $1500 \mathrm{ppm}$ chlorine, and $0.87 \%$ sulfur. Data on the petcoke consumed at this facility was not available.

\subsubsection{We Energies' Pleasant Prairie Power Plant}

Tests were conducted at We Energies' Pleasant Prairie Power Plant (P4), Units 1 and 2. Evaluations began November 3, 2003 at P4 and continued until January 22, 2004.

The boilers are R-Turbo units rated at $605 \mathrm{MW}$ each. Particulate emissions are controlled by an ESP. Unit 1 has been retrofitted for a SCR for $\mathrm{NO}_{\mathrm{x}}$ control, but currently the catalyst is not in place. Unit 2 has also been retrofitted for an SCR with the catalyst installed and operational. Based on 1999 ICR (7) coal data, the PRB coal at this site has $14 \mathrm{ppm}$ chlorine and $0.11 \mu \mathrm{g} / \mathrm{g}$ mercury.

\subsection{Description of Equipment}

\subsubsection{Fixed-Bed Adsorption Test Equipment}

Determination of the equilibrium adsorption capacity of each candidate sorbent was evaluated by mixing the sorbent with quartz sand and packing the mixture in a Teflon sorbent reaction column. Mixing the sorbent with sand reduced the pressure drop through the column and prevented gas tracking through the column. The bed material was supported by a perforated Teflon disk and packed with quartz wool. The column and upstream tubing were heated and temperature controlled to the specific test temperature for at least 1 hour prior to initiating flow through the column. A further description of the fixed-bed equipment is presented in Appendix A.

During testing, a particulate-free gas sample was provided to the reaction column. An Apogee QSIS ${ }^{\text {тм }}$ (QSIS) probe was used during field evaluations to inertially separate and filter the fly ash from the flue gas sample. A sample flow of approximately 1-2 liters/minute was continuously passed through the column. The flue gas flowed downward through the column to minimize the chance of selective flow or channeling through the bed. Mercury measurements were made at the inlet and outlet of the column. The amount of mercury exiting the column was measured on a semi-continuous basis until 100\% mercury breakthrough was detected.

Following the fixed-bed sorbent evaluation, mercury adsorption breakthrough curves were generated. The percent breakthrough was determined as a function of time by normalizing the measured mercury concentration at the outlet of the sorbent bed to the inlet mercury concentration. The adsorption capacity of the sorbent ( $\mu \mathrm{g} \mathrm{Hg}$ adsorbed/g sorbent) at any given time " $t$ " is determined by summing the total mass of mercury adsorbed through time " $t$ " (area above the breakthrough curve) and dividing by the sorbent mass. The equilibrium adsorption capacity is defined by the time when the outlet mercury concentration is first equal to the inlet concentration. 


\subsubsection{Slipstream Injection Equipment}

The PoCT system is comprised of several small modules that can be configured in series or interchanged as required by the test progam. The gas extraction assembly uses a temperature controlled probe, flow meter, flow control valve, and several induced draft fans. The extraction probe is a 0.75 to 1.5 -inch diameter stainless steel pipe, depending upon the flowrate for the configuration. The length of the probe is determined following a velocity traverse of the duct so that the gas extraction location is at the duct's average gas velocity. After extracting a slipstream of gas from the duct, the gas passes through a QSIS $^{\text {TM }}$ filter where a particulate-free sample can be obtained for vapor-phase mercury analysis. The gas then flows through the particulate control module(s), another QSIS filter, through a venturi to measure flow, and an automatic flow control valve. The gas flow is controlled from 10 to $50 \mathrm{acfm}$ depending on the configuration and test parameters.

During residence chamber testing, sorbent is injected into an 8-inch diameter stainless steel tube approximately 60 -inches in length. The flow through the tube is maintained at nominally $30-50 \mathrm{acfm}$. This arrangement minimizes wall-effects caused by the smaller diameter inlet piping and transition zones. A sketch of the residence tube arrangement is shown in Figure 1. Two outlet QSIS filters were installed in the residence tube to allow measurement at two different residence times.

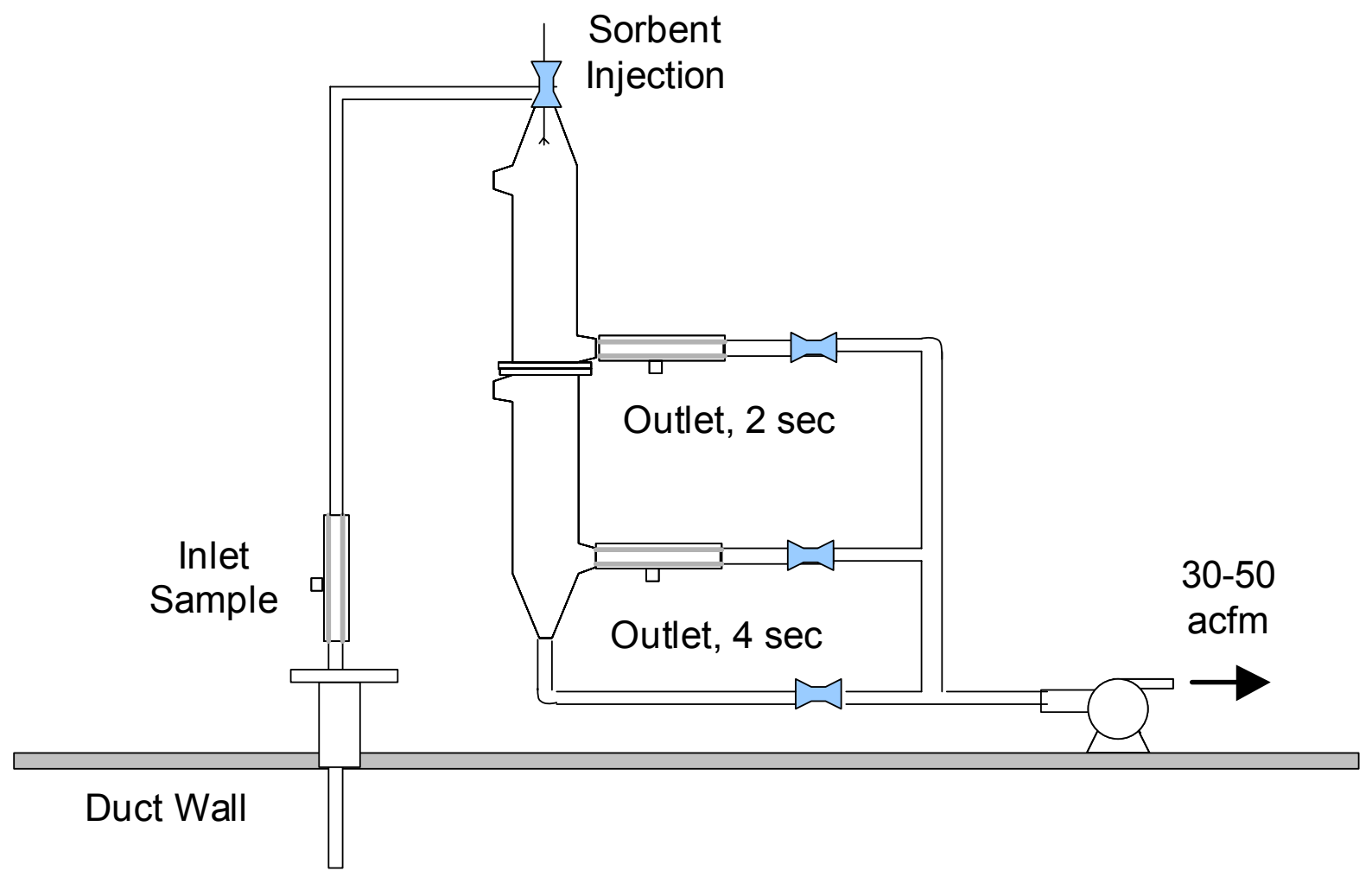

Figure 1. PoCT Residence Time Chamber. 
During COHPAC testing, two pulse-jet modules were installed in parallel downstream of a tube-wire ESP to assess the differences in sorbent performance with different bag materials. A COHPAC module designed for sorbent injection is also called TOXECON. Sorbent was injected upstream of the pulse-jet baghouse module and collected on the bag. The filter bags were 24 inches long and had a flat width of 7.562 inches. Bag cleaning was initiated manually during testing and was performed off-line. A sketch of the PoCT TOXECON configuration is shown in Figure 2. As shown, the PoCT pulse-jet module is a top-entry design, which minimizes particulate fall-out into the hopper that often is a concern in small-scale systems.

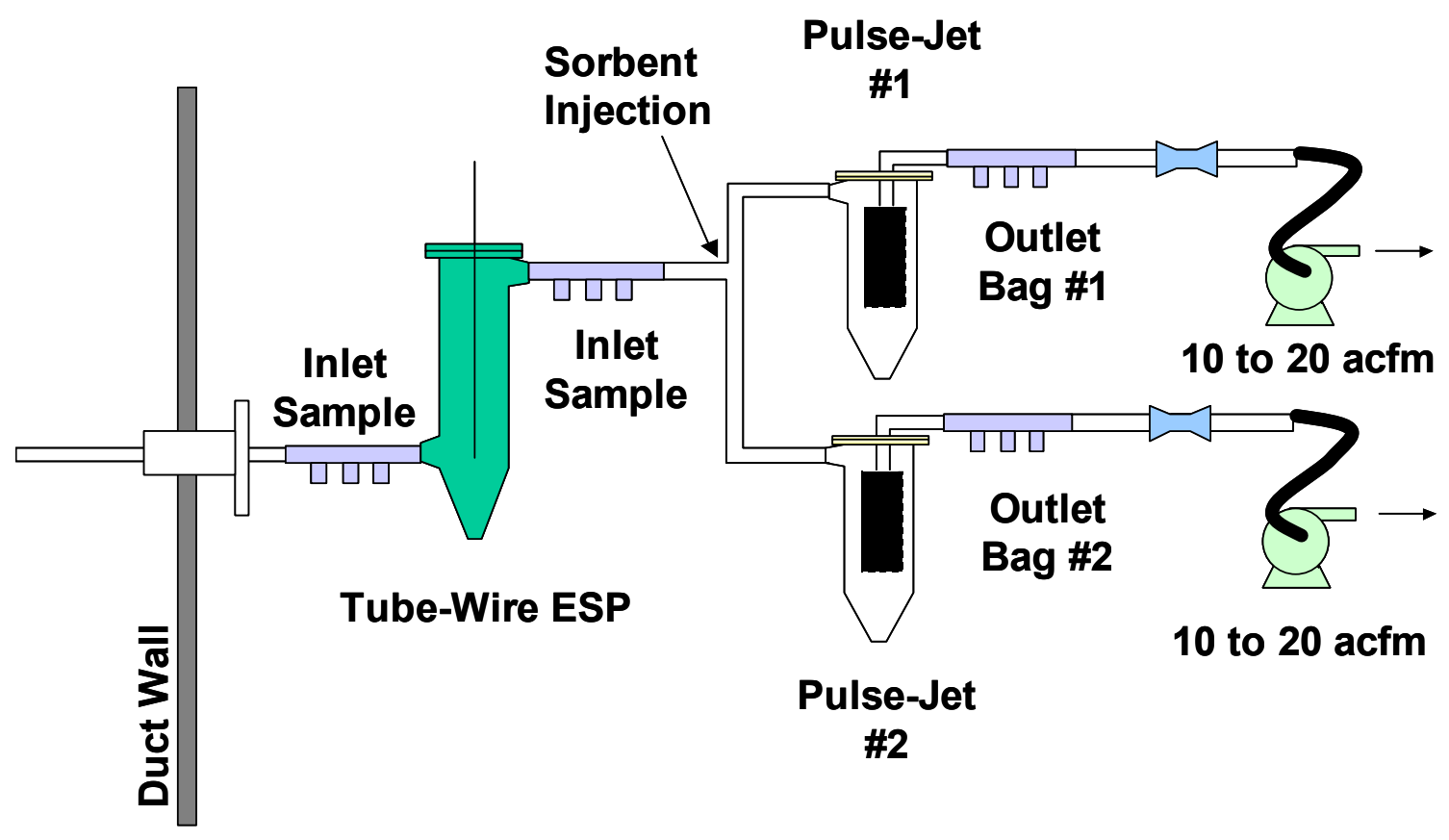

Figure 2. PoCT configured for TOXECON evaluations.

The sorbent injection assembly consists of a small screw feeder and an air eductor. Compressed air is used to carry the sorbent from the eductor to the PoCT injection port. Several custom-designed screw helixes were prepared to provide the low injection rates required for some sorbents during this program.

\subsubsection{By-Product Analysis Equipment}

During long-term sorbent evaluations at Powerton and VAPP, fly ash and spent sorbent (collectively referred to as by-product) were collected in the baghouse hoppers on the PoCT system. These by-product samples were sent to the URS Group to perform air stability and leaching (using EPA Method 1312- Synthetic Precipitation Leaching Procedure (SPLP)) evaluations. Equipment used during by-product evaluations are described in Appendix B. 


\subsection{Sorbent Descriptions and Selection}

Sorbent properties are the most important parameters controlling the effectiveness of a duct injection process for mercury removal. Under numerous sorbent development programs by EPRI and others, many promising low cost mercury sorbents and processes have been identified. A thorough characterization of over 1,000 sorbents and over 100 fly ashes has been conducted, including evaluating the sorbent chemistry, specific surface area, pore size, particle size, and carbon content of fly ash samples. Additional research has been conducted to determine the effect of treating sorbents such as sulfur impregnation. The proposed sorbents have been tested over two different flue gas conditions. These conditions include simulated flue gas from bituminous coal and subbituminous PRB coal, with both elemental mercury and mercuric chloride. Conditions were chosen to examine the effects of composition and to simulate the flue gases of different coal types. Testing was also conducted at $275^{\circ} \mathrm{F}$ and $325^{\circ} \mathrm{F}$ to determine the effect of temperature on sorbent performance.

The most promising novel mercury sorbents developed to date include the following:

- Activated carbon prepared from high organic sulfur coal

- Activated carbon from biomass and waste tires

- Sulfur impregnated sorbents

- Zeolites

- Carbon separated from fly ash (LOI) and unseparated fly ash

Laboratory performance evaluations of forty-seven sorbents were conducted in simulated low sulfur Eastern bituminous flue gas and twenty-seven in a simulated PRB flue gas by the URS Group. A list of sorbent vendors and their sorbents are presented in Appendix C. These sorbents were identified as potential sorbents for testing at VAPP and Powerton based upon economic information provided by the sorbent manufacturers and tested during this program, or by using existing data from URS Group's testing outside this program. A control sample, FGD activated carbon, was also tested as part of the program. Based upon the results of the laboratory fixed-bed screening tests and estimated sorbent costs, eight sorbents were chosen and characterized in the fixed-bed adsorption test device at Powerton and seventeen sorbents for evaluations at VAPP. Of these, five sorbents were chosen as low-cost candidates for injection testing at Powerton and nine sorbents were chosen for VAPP. Eight additional sorbents were added to the screening process after the fixed-bed evaluations were completed at VAPP either by request of the DEO/NETL Program Manager or because suppliers had additional sorbents developed during the project's time frame that meet the original vendor solicitation. Nineteen sorbents were evaluated at P4 with the slipstream PoCT system. The results of the laboratory and field fixed-bed tests for the chosen injection sorbents are presented in Table 1 for Powerton and Table 2 for VAPP. Descriptions of the sorbents are presented in Tables 3 to 5. Different adsorption capacities were measured for the individual 
sorbents depending on the location of the evaluations (laboratory or field). This supports the need for field evaluations on sorbents that may be considered for mercury control technology. Results from all laboratory fixed-bed tests are included in Appendix D.

Table 1. Sorbent Equilibrium Adsorption Capacity Measured in the Laboratory and at Powerton.

\begin{tabular}{|c|c|c|c|}
\hline Sorbent & $\begin{array}{c}\text { Test Temp } \\
\left({ }^{\circ} \mathrm{F}\right)\end{array}$ & $\begin{array}{c}\mathrm{Lab}, \mathrm{Hg}^{\mathbf{0}} \\
\text { Adsorption Capacity } \\
\mu \mathrm{g} / \mathrm{g} @ 50 \mathrm{mg} / \mathrm{Nm}^{3}\end{array}$ & $\begin{array}{c}\text { Powerton } \\
\text { Adsorption Capacity } \\
\mu \mathrm{g} / \mathrm{g} @ 50 \mathrm{mg} / \mathrm{Nm}^{3}\end{array}$ \\
\hline FGD & 325 & 450 & 264 \\
\hline TDAC & 325 & 227 & 760 \\
\hline \multirow[t]{2}{*}{ AFR-g } & 275 & 314 & \multirow[b]{2}{*}{1,003} \\
\hline & 325 & & \\
\hline CFA & 325 & 847 & 259 \\
\hline \multirow[t]{2}{*}{ CS80 } & 275 & 1,313 & \multirow[b]{2}{*}{328} \\
\hline & 325 & & \\
\hline \multirow[t]{2}{*}{ HOK300S } & 275 & 1,449 & \multirow[b]{2}{*}{670} \\
\hline & 325 & & \\
\hline
\end{tabular}

Table 2. Sorbent Equilibrium Adsorption Capacity Measured in the Laboratory and at VAPP.

\begin{tabular}{|c|c|c|c|}
\hline Sorbent & $\begin{array}{c}\text { Test Temp } \\
\left({ }^{\circ} \mathrm{F}\right)\end{array}$ & $\begin{array}{c}\mathrm{Lab} \mathrm{Hg}^{\mathrm{O}} \\
\text { Adsorption Capacity } \\
\mu \mathrm{g} / \mathrm{g} @ \mathbf{5 0} \mu \mathrm{g} / \mathrm{Nm}^{3}\end{array}$ & $\begin{array}{c}\text { VAPP } \\
\text { Adsorption Capacity } \\
\mu \mathrm{g} / \mathrm{g} @ 50 \mu \mathrm{g} / \mathrm{Nm}^{3}\end{array}$ \\
\hline FGD & $\begin{array}{l}290 \\
275\end{array}$ & 618 & 1,346 \\
\hline CS80 & $\begin{array}{l}290 \\
275\end{array}$ & $990 *$ & 1,094 \\
\hline$\overline{\mathrm{CFA}}$ & $\begin{array}{l}290 \\
275\end{array}$ & 1,288 & 2,004 \\
\hline TDAC & $\begin{array}{l}290 \\
275\end{array}$ & 444 & 568 \\
\hline HOK & $\begin{array}{l}290 \\
275\end{array}$ & $1,750 *$ & 480 \\
\hline PSI-C & $\begin{array}{l}290 \\
275\end{array}$ & $4,047 *$ & 55 \\
\hline LAC & $\begin{array}{l}290 \\
275 \\
\end{array}$ & 555 & 927 \\
\hline $\begin{array}{c}\text { ARK E-5-CN- } \\
02 * *\end{array}$ & $\begin{array}{l}290 \\
275\end{array}$ & $115^{*}$ & 16 \\
\hline STI-20513-B & 290 & & 393 \\
\hline Sorbtech L ** & $\begin{array}{l}290 \\
275\end{array}$ & $1,719^{*}$ & 1,194 \\
\hline
\end{tabular}

* Data for $\mathrm{Hg}^{0}$ were not available; measurements are $\mathrm{HgCl}_{2}$ adsorption capacity $\mu \mathrm{g} / \mathrm{g} @ 50 \mu \mathrm{g} / \mathrm{Nm}^{3}$

** An alternate sorbent was submitted by supplier that satisfies the requirements 
Commercially available FGD carbon, generated from lignite coal, was used during all configurations of PoCT testing at all three sites as the benchmark sorbent. The bulk FOB cost of FGD was $\$ 0.42 / 1 \mathrm{~b}$ for this comparison

Another sorbent, IAC, is an iodine-treated sorbent that has demonstrated promising performance during recent EPRI sorbent evaluations. Due to the extra processing steps for the IAC, the cost of this sorbent is over $\$ 7 / \mathrm{lb}$ as compared to nominally $\$ 0.42 / \mathrm{lb}$ for the FGD. Therefore this sorbent was tested only in screening tests in the TOXECON configuration and was not considered for long-term tests.

Cost estimates for the other experimental sorbents, as provided by the developers, are at least $25 \%$ less than the cost of commercially available FGD. The HOK is a commercial product from Germany and the cost quoted by the vendor is approximately $50 \%$ the current cost of FGD, not including freight from the nearest Atlantic port for the HOK or Marshall, Texas for the FGD.

The five sorbents tested at Powerton are shown in Table 3. Table 4 and Table 5 are the sorbents that were evaluated at VAPP and P4, respectively. Vendor information on the sorbents is presented in Appendix D. The sorbents are categorized as non-carbon-based (Other), carbon-based, no activation (Carbon), activated carbon-based (AC), and treated carbon-based (TC).

Table 3. Descriptions of Sorbents Evaluated at Powerton.

\begin{tabular}{|c|c|c|}
\hline Sorbent ID & Description & Category \\
\hline FGD & $\begin{array}{c}\text { Texas lignite coal-based commercial carbon, } \mathrm{d} 50 \\
=18 \mu \mathrm{m}\end{array}$ & $\mathrm{AC}$ \\
\hline TDAC & Experimental waste-tire based activated carbon & $\mathrm{AC}$ \\
\hline CFA & Pilot kiln corn-char; experimental, d50 $=15 \mu \mathrm{m}$ & Carbon \\
\hline CS80 & Experimental carbon from soot, $\mathrm{d} 50=6.2 \mu \mathrm{m}$ & Carbon \\
\hline $\mathrm{HOK}$ & $\begin{array}{l}\text { German lignite coal-based commercial carbon, } \\
\qquad \mathrm{d} 50=19 \mu \mathrm{m}\end{array}$ & $\mathrm{AC}$ \\
\hline STI-B & Separated and treated fly ash & Other \\
\hline
\end{tabular}


Table 4. Descriptions of Sorbents Evaluated at VAPP.

\begin{tabular}{|c|c|c|}
\hline Sorbent ID & Description & Category \\
\hline FGD & $\begin{array}{l}\text { Texas lignite coal-based commercial carbon, } \mathrm{d} 50 \\
=18 \mu \mathrm{m}\end{array}$ & $\mathrm{AC}$ \\
\hline TDAC & Experimental waste tire-based activated carbon & $\mathrm{AC}$ \\
\hline CFA & Pilot kiln corn-char; experimental, d50 $=15 \mu \mathrm{m}$ & Carbon \\
\hline CS80 & Experimental carbon from soot, $\mathrm{d} 50=6.2 \mu \mathrm{m}$ & Carbon \\
\hline $\mathrm{HOK}$ & $\begin{array}{l}\text { German lignite coal-based commercial carbon, } \\
\qquad \mathrm{d} 50=19 \mu \mathrm{m}\end{array}$ & $\mathrm{AC}$ \\
\hline $\begin{array}{l}\text { STI-020513-B, 020930- } \\
\text { C, A }\end{array}$ & Separated and treated fly ash & Other \\
\hline IAC and IAC 020430-B & $\begin{array}{l}\text { Coconut shell-based, iodine impregnated carbon, } \\
\qquad \mathrm{d} 50=25 \mu \mathrm{m}\end{array}$ & $\mathrm{TC}$ \\
\hline S-1 and E-1-S & Treated fly ash & Other \\
\hline LAC & Lignite activated carbon & $\mathrm{AC}$ \\
\hline PSI-C & Modified zeolite & Other \\
\hline A10 and $\mathrm{G}$ & $\begin{array}{l}\text { Activated carbon with various treatment } \\
\text { applications }\end{array}$ & $\mathrm{TC}$ \\
\hline $\begin{array}{l}\text { 2002-8680 and 2002- } \\
8567\end{array}$ & $\begin{array}{c}\text { Activated carbon with various treatment } \\
\text { applications }\end{array}$ & $\mathrm{TC}$ \\
\hline
\end{tabular}

Table 5. Descriptions of Sorbents Evaluated at P4.

\begin{tabular}{|c|c|c|}
\hline Sorbent ID & Description & Category \\
\hline FGD & $\begin{array}{c}\text { Texas lignite coal-based commercial carbon, } \\
\mathrm{d} 50=18 \mu \mathrm{m}\end{array}$ & $\mathrm{AC}$ \\
\hline A6, A5 & Activated carbon base, treated $\sim 15 \mathrm{um}$ & $\mathrm{TC}$ \\
\hline MC-40, MG-20 & Coal based, no added chemicals, 325 mesh & AC \\
\hline LAC & Lignite activated & AC \\
\hline CFA & Pilot kiln corn-char; experimental, d50 $=15 \mu \mathrm{m}$ & Carbon \\
\hline CS80 & Experimental carbon from soot, d50 $=6.2 \mu \mathrm{m}$ & Carbon \\
\hline IAC & Coconut shell-based, iodine impregnated carbon, & TC \\
& d50 $=25 \mu \mathrm{m}$ & \\
\hline AMS & Amended silicates $($ CL-EA-X004) & Other \\
\hline FA1 & Low density coal-based & Carbon \\
\hline CR325A & Bamboo-based & TC \\
\hline CR325D & Bituminous coal based, charred and activated, & AC \\
\hline UMI-FG9B & Activated carbon, treated, 325 mesh & TC \\
\hline Sample 1 and 2 & Combustion byproduct & Other \\
\hline Thief & German lignite coal-based commercial carbon, \\
d50 = 19 $\mu \mathrm{m}$ & AC \\
\hline HOK & Zeolite-based, 400 mesh & Other \\
\hline PRA58 &
\end{tabular}




\subsection{Results and Discussion}

\section{$\underline{4.1 \text { Sorbent Screening Results }}$}

\subsubsection{Powerton Screening Results}

Injection screening was conducted at a single injection rate and a gas temperature of $300^{\circ} \mathrm{F}$ using the PoCT system configured as TOXECON. During the initial screening period, the sorbents were injected at an injection rate of nominally $1.5 \mathrm{lb} / \mathrm{Mmacf}$ for 20 minutes to provide a direct comparison of performance. Mercury removal was measured across a Teflon coated woven fiberglass bag. The mercury removal measured during injection of each novel sorbent and FGD is shown in Figure 3. The yellow bars indicate sorbents that are not carbon based, green bars indicate sorbents that are carbon based but no activation, and the blue bars indicate carbon-based sorbents with activation. All carbon-based sorbents demonstrated similar performance, greater than $80 \%$ mercury removal, except the TDAC. This material agglomerated prior to feeding. Previous samples of this material did not demonstrate these physical properties. It is possible that the lower mercury removal performance is due to the agglomerating nature of this sample.

Following the initial screening tests, the performance of the two most promising sorbents (CFA and HOK) and FGD were characterized by varying the injection concentration and the operating temperature of the COHPAC baghouse. The most promising sorbents were chosen based upon performance and cost. As mentioned above, the HOK is a commercial product from Germany and the cost quoted by the vendor is approximately $50 \%$ the current cost of FGD, not including freight from the nearest Atlantic port for the HOK or Marshall, Texas for the FGD. The CFA was chosen for testing at Powerton because the corn material is available from a corn processing plant near Powerton, thus the shipping costs for the sorbent are expected to be low reducing the overall cost of the product. These factors made these two sorbents the most cost-effective of the group. 


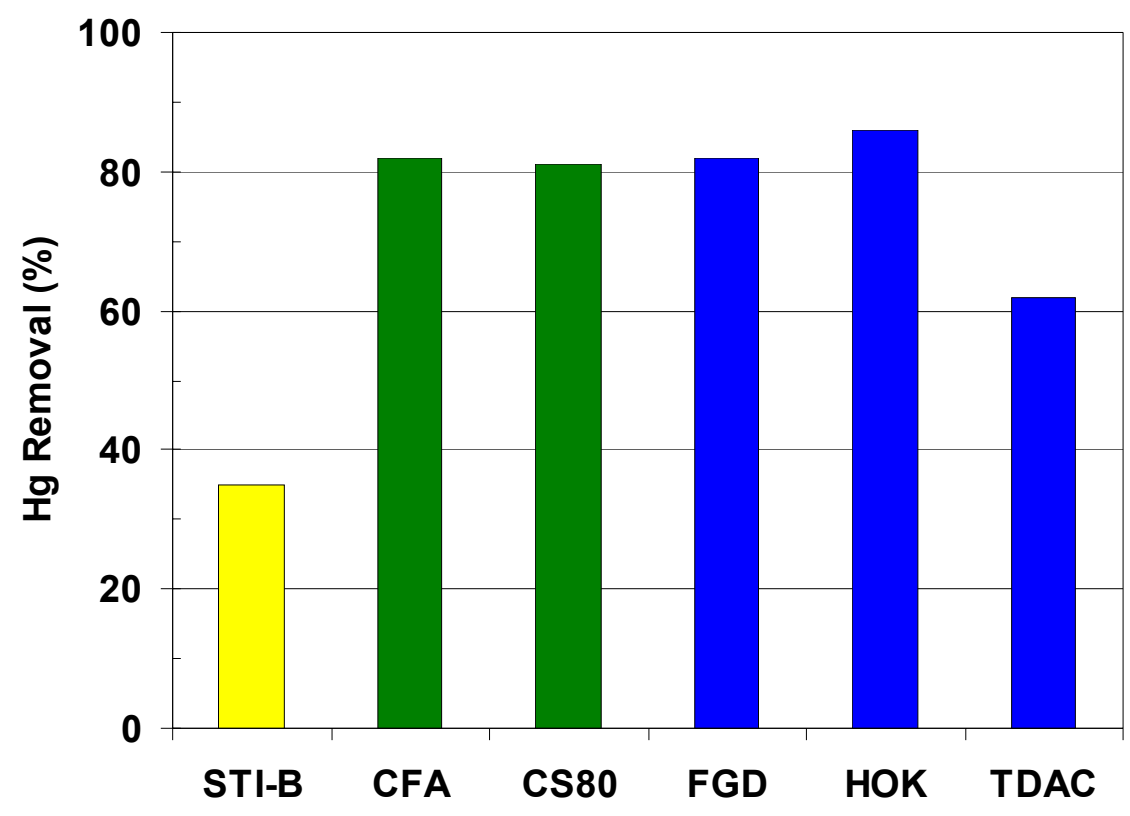

Figure 3. Results from sorbent screening at Powerton. Injection concentration $\sim 1.5 \mathrm{lb} /$ Mmacf.

\subsubsection{VAPP Screening Results}

Sorbent injection screening was conducted at a single injection rate and a gas temperature of $315^{\circ} \mathrm{F}$ using the PoCT system configured as TOXECON. During the initial screening period, the sorbents were injected at an injection rate of nominally $2.0 \mathrm{lb} / \mathrm{Mmacf}$ for 120 minutes to provide a direct comparison of performance. The mercury removal was measured across a Teflon coated woven fiberglass bag. The mercury removal measured during injection of each novel sorbent and FGD is shown in Figure 4. The yellow bars indicate sorbents that are not carbon based, green bars indicate sorbents that are carbon based but no activation, blue bars indicate carbon based sorbents with activation, and red bars indicated carbon based sorbents with additional treatments. Six of the carbon-based sorbents (FGD, CFA, LAC, 2002-8680, 2002-8567, and A10) demonstrated similar performance (mercury removal due to sorbent injection of greater than $90 \%$ ). Three of the sorbents (HOK, CS80, and $\mathrm{G}$ ) removed greater than $70 \%$ but less than $90 \%$ of the mercury in the flue gas. Six of the sorbents (E-1-S, IAC 020430-B, PSI-C, 020513-B, 020930-C, and TDAC) removed less than $50 \%$ of the incoming mercury. Two of the sorbents, S1 and A, which were in the "other" category, showed no appreciable mercury removal. 


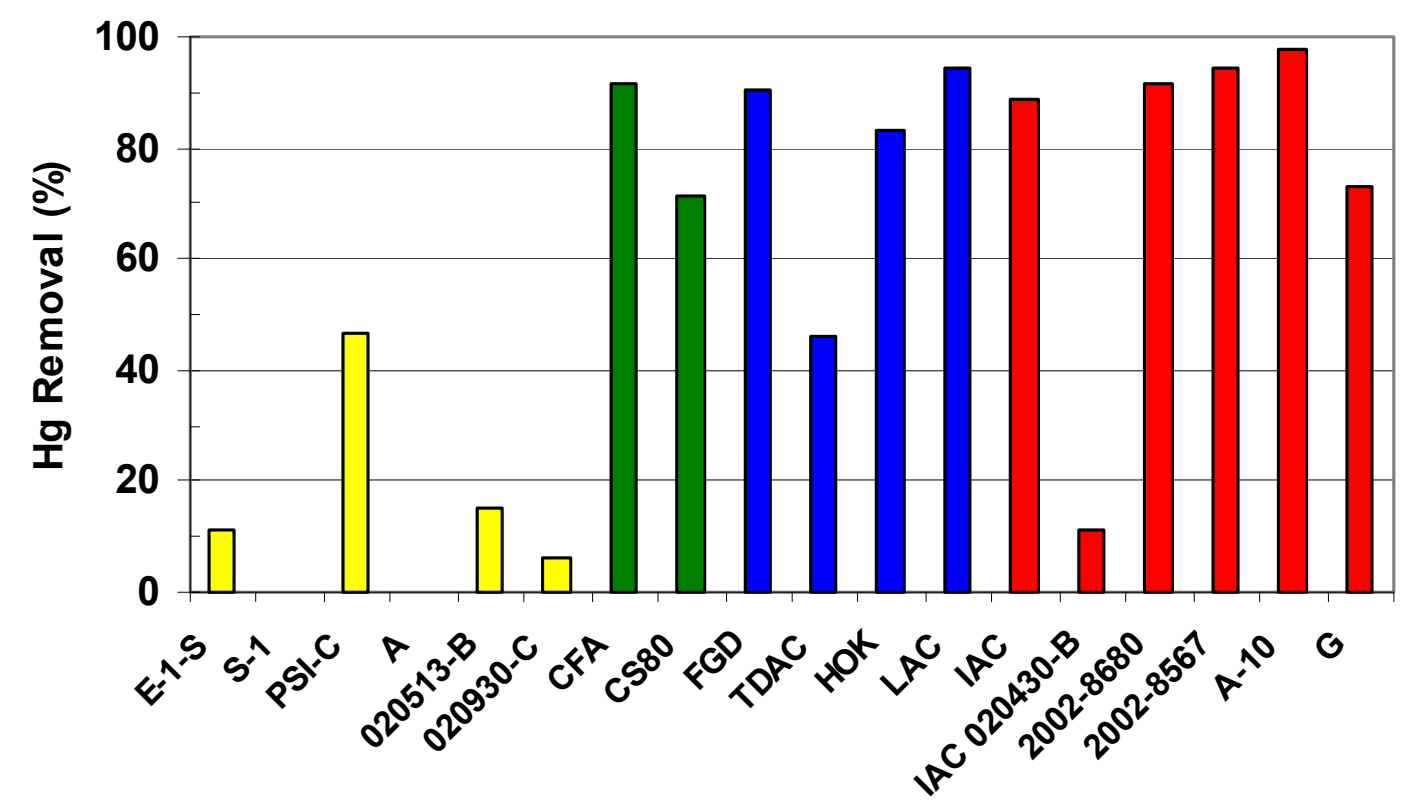

Figure 4. Results from sorbent screening at VAPP at an injection concentration $\sim 2.0 \mathrm{lb} /$ Mmacf.

Following the initial screening tests, the performance of the two most promising sorbents (CFA and A10) and FGD were characterized by varying the injection concentration and the operating temperature of the COHPAC baghouse. The most promising sorbents were chosen based upon performance and cost. The CFA was chosen for testing at VAPP because the corn material can be processed nearby, thus the shipping costs for the sorbent are expected to be low reducing the overall cost of the product. Sorbent A10 demonstrated excellent mercury removal and meets the supplier solicitation requirements. These factors made these two sorbents the most cost-effective of the group.

\subsubsection{P4 Screening Results}

At P4, injection screening on nineteen sorbents was conducted at a single batch injection rate (equivalent to $1 \mathrm{lb} / \mathrm{Mmacf}$ for 1 hour) and a gas temperature of $300^{\circ} \mathrm{F}$ using the PoCT configured as a COHPAC baghouse. The batch injection rate used during screening was equivalent to 1.09 grams of sorbent batch injected into the system at two equal quantities (0.545 grams) approximately four minutes apart.

Mercury removal was measured across a Teflon coated woven fiberglass bag. The mercury removal measured during injection of each sorbent is shown in Figure 5. Again, the yellow bars indicate sorbents that are not carbon based, green bars indicate sorbents that are carbon based but no activation, blue bars indicate carbon-based sorbents with activation, and red bars indicated carbon-based sorbents with additional treatments. Carbon-based sorbents, in general, performed better than those sorbents in the "other" 
category. The IAC (not shown in Figure 5) was evaluated at $0.5 \mathrm{lb} / \mathrm{Mmacf}$ with a result of $70 \%$ mercury removal.

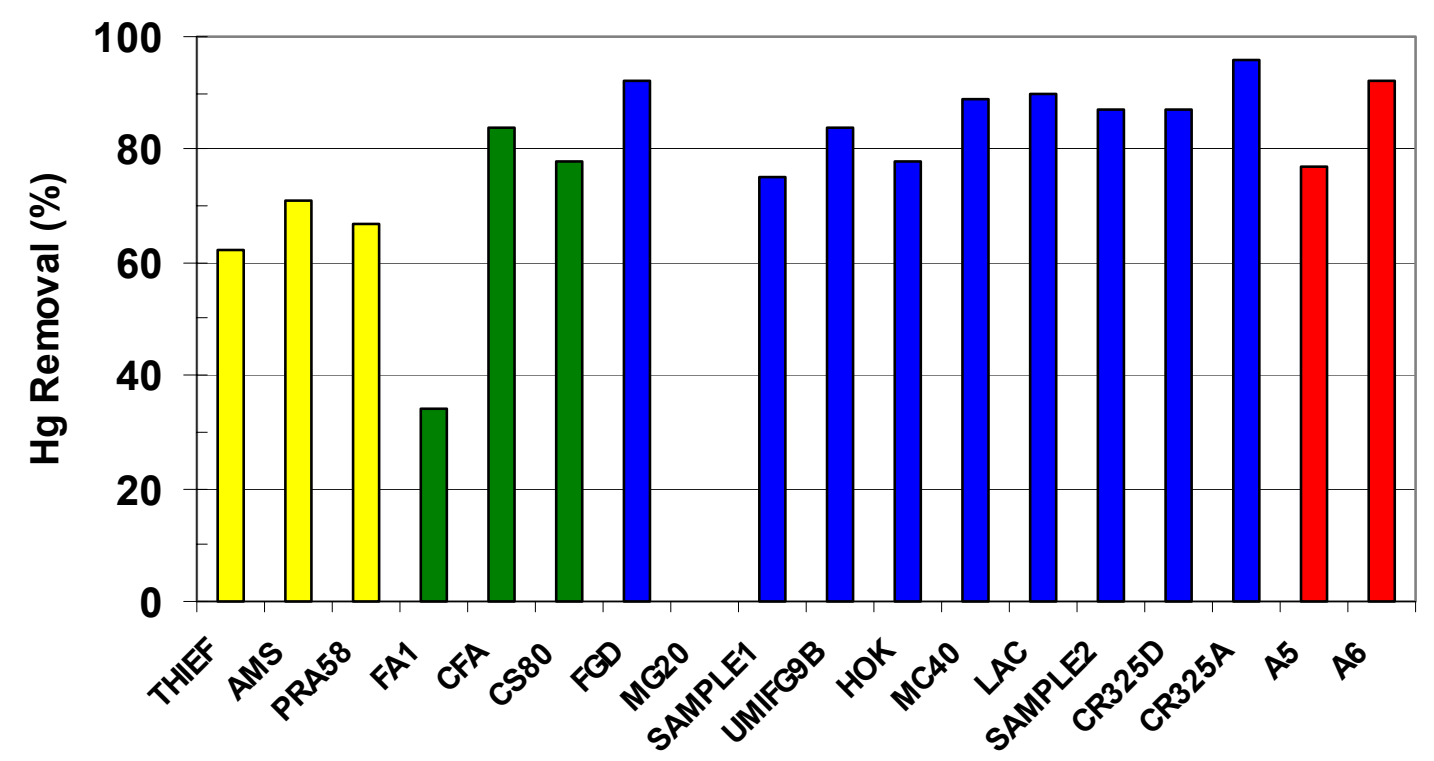

Figure 5. Results from sorbent screening on P4's Unit 1. Batch injection concentration equivalent to $1 \mathrm{lb} / \mathrm{Mmacf}$ for 1 hour.

Following the initial screening evaluations on Unit 1, the performance of the three selected sorbents (AMS, A6, and CR325D) and FGD were characterized by varying the batch injection concentration and the operating temperature of the COHPAC baghouse. The selected sorbents were chosen based upon screening performance, novel idea, and sorbent cost. CR325D was chosen over CR325A because the base-material was biomass (bamboo) and was different from biomass sorbents previously evaluated. Cost estimates for the experimental sorbents, as provided by the developers, are at least $25 \%$ less than the cost of commercially available FGD. Both the A6 and AMS were chosen for testing at $\mathrm{P} 4$ because the sorbents, according to the suppliers, would not affect fly ash sales.

\subsection{Parametric and Long-term Evaluation Results}

\subsubsection{Powerton Parametric Results}

During parametric testing, the mercury removal across the baghouse was measured at three sorbent injection rates and two gas temperatures. HOK, CFA and FGD were each tested.

Sorbent performance with respect to gas temperature and injection concentration is presented in Figure 6. As shown, the impact of increasing the temperature from $300^{\circ} \mathrm{F}$ to $350^{\circ} \mathrm{F}$ is insignificant, except possibly for the CFA at the lowest injection rate, where some degradation was seen. 


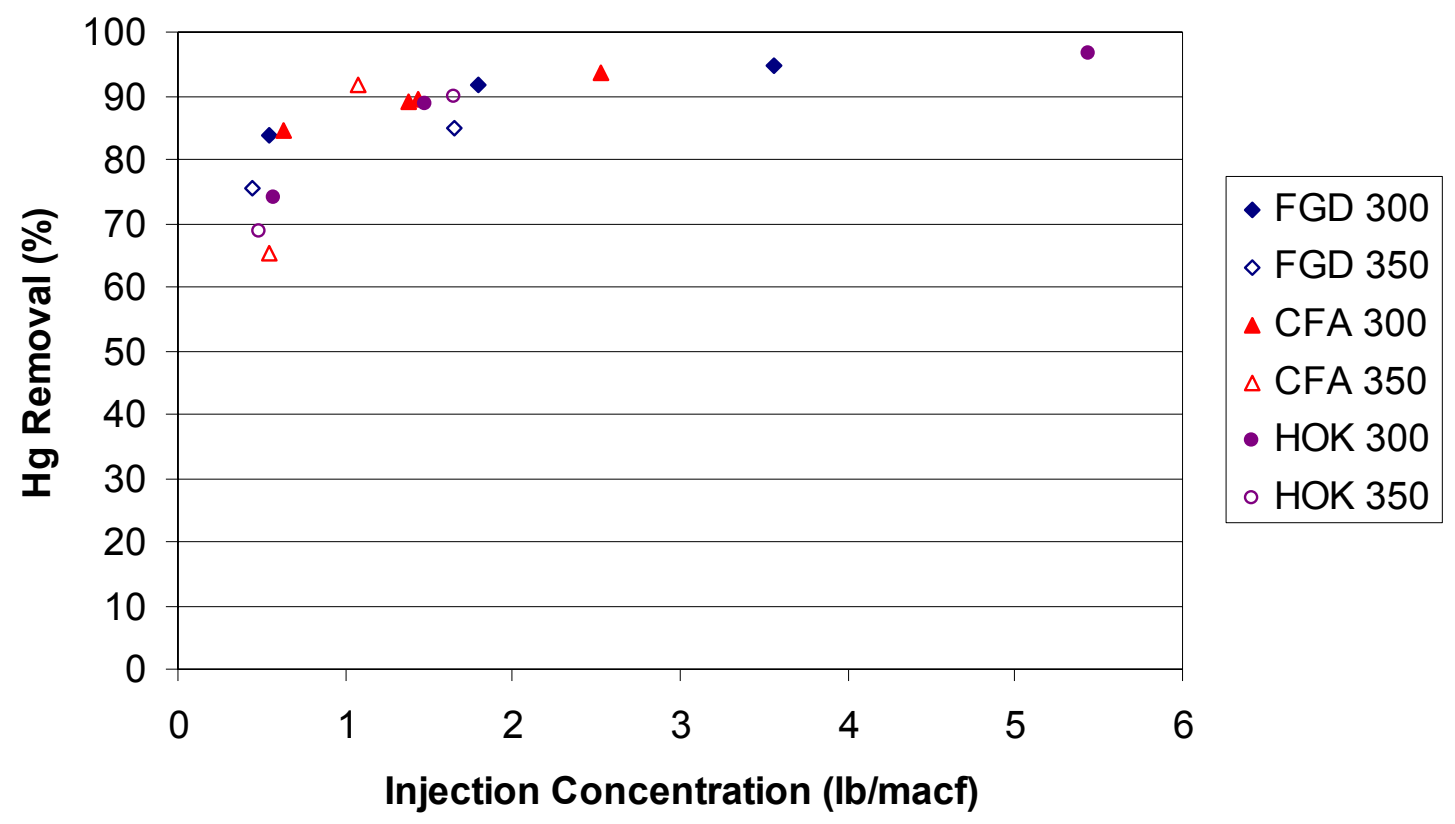

Figure 6. Comparison of mercury removal at $300^{\circ} \mathrm{F}$ and $350^{\circ} \mathrm{F}$ at Powerton.

An iodine-impregnated activated carbon (IAC) was also evaluated to determine if injection of a treated carbon would result in higher mercury removal. The IAC was screened at a lower injection concentration than the other sorbents. An injection concentration of $0.6 \mathrm{lb} / \mathrm{Mmacf}$ resulted in $72 \%$ mercury removal during the screening test, as compared to $82 \%$ removal for FGD at an injection concentration of $1.5 \mathrm{lb} / \mathrm{Mmacf}$. To better compare mercury removal performance, the screening results for the IAC and FGD were reviewed alongside the parametric results from the FGD tests. During the parametric tests, the mercury removal at $1.5 \mathrm{lb} / \mathrm{Mmacf}$ was $93 \%$ (as compared to $82 \%$ during the short screening test). At an FGD injection concentration of $0.6 \mathrm{lb} / \mathrm{Mmacf}$, the mercury removal was still relatively high at $84 \%$. This data suggests that the IAC did not demonstrate better mercury removal performance than the FGD in the TOXECON configuration at Powerton.

\subsubsection{Powerton Long-term Results}

Following parametric testing, a continuous injection evaluation was conducted for CFA, $\mathrm{HOK}$, and FGD in the TOXECON configuration. Two different bag fabrics were installed in the baghouse compartments of the PoCT, one was a Teflon coated fiberglass and the other was a 7.0 denier PPS felt Torcon. The longer-term injection test was conducted for 8 to 12 hours at a targeted injection rate of $2 \mathrm{lb} / \mathrm{Mmacf}$ and a temperature of $300^{\circ} \mathrm{F}$. Inlet mercury levels ranged from 5 to $7.5 \mu \mathrm{g} / \mathrm{Nm} 3$. The mercury removal across the bag increased for approximately 2 hours before leveling off to around $90 \%$ for 
all sorbents. A sample of the material collected in the baghouse hopper during the extended HOK injection test was re-injected to determine the potential of recycling sorbents in a TOXECON configuration. At the screening injection concentration, the recycled $\mathrm{HOK} /$ fly ash demonstrated 53\% mercury removal as compared to $83 \%$ mercury removal with fresh HOK sorbent. The product collected in the hopper during the extended test was nominally $50 \%$ sorbent.

By-products collected in each baghouse hopper were sent to the URS Group for byproduct evaluations. Results are presented later in the report.

\subsubsection{VAPP Parametric Results}

Mercury removal across the baghouse during the parametric evaluations of CFA, A10, and FGD was measured at three sorbent injection rates and two gas temperatures. The sorbents were injected upstream of the baghouse modules in the TOXECON configuration.

Sorbent performance with respect to gas temperature and injection concentration is presented in Figure 7. As shown, the impact of increasing the temperature from $315^{\circ} \mathrm{F}$ to $350^{\circ} \mathrm{F}$ slightly increased the mercury removal, except possibly for the FGD at the lowest injection rate, where some degradation was seen.

The baseline mercury removal across the TOXECON assembly was not consistent. The natural mercury removal ranged from $5 \%$ to $60 \%$ depending on the time of the evaluations. LOI has been shown to influence mercury removal in other research. In an earlier study performed by Apogee for EPRI, fly ash analysis was performed and the LOI was measured to be at $35 \%$ for both daytime and nighttime operations. EPRI also looked at the variation in steam flow and found that it only varied by $15 \%$ for a two-day sample period. However, the loading was nearly twice as high during the evening as during the day, and the size distribution of the night sample was somewhat smaller than the sample collected during the day. Soot blowing did occur occasionally at VAPP and the data collected during those periods was excluded in the analysis. The percent mercury removal presented in this report is percent removal due to sorbent injection. 


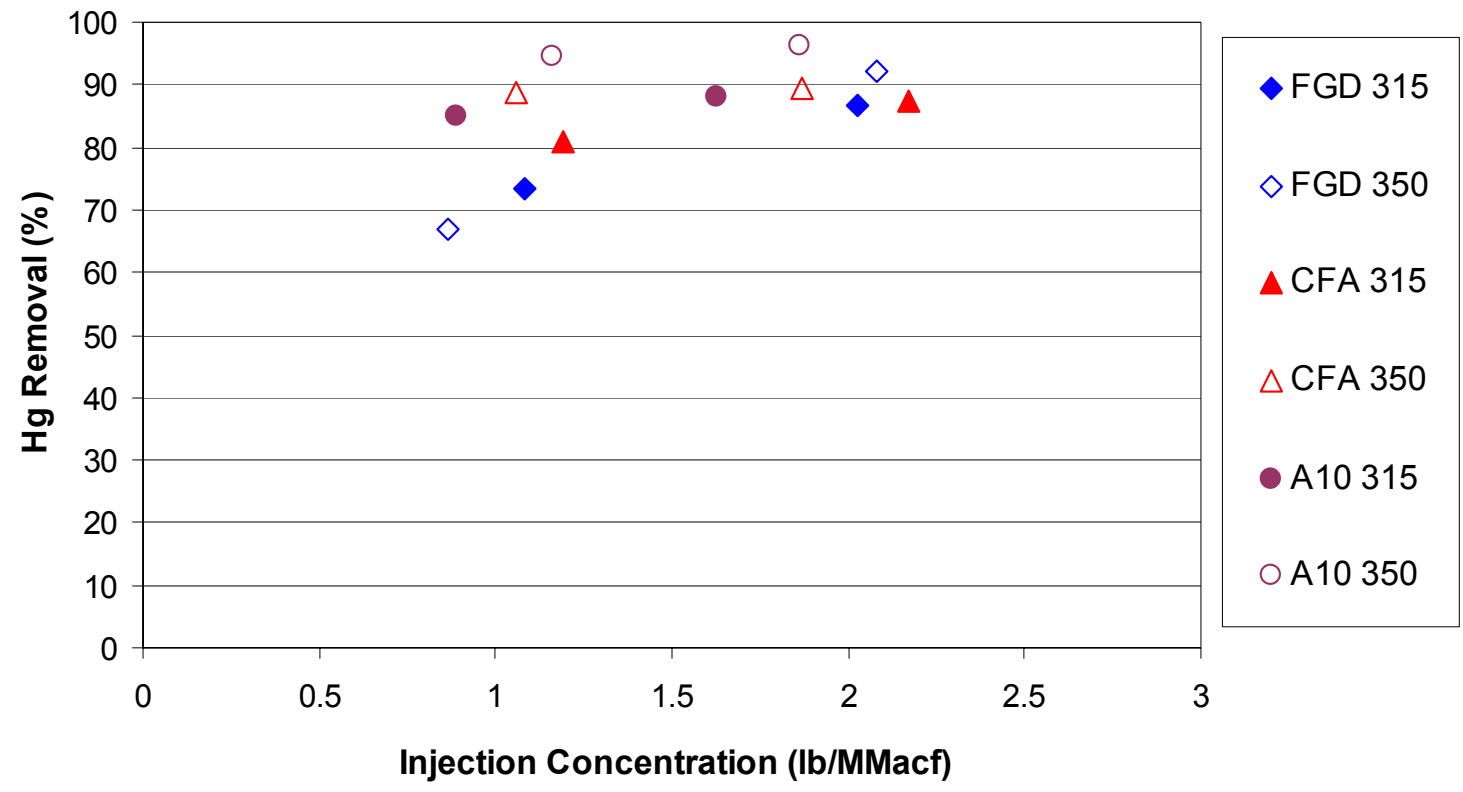

Figure 7. Comparison of mercury removal for sorbents at VAPP at $315^{\circ} \mathrm{F}$ and $350^{\circ} \mathrm{F}$.

\subsubsection{VAPP Long-term Results}

Following parametric testing, a long-term continuous injection evaluation was conducted for the two sorbents (CFA and A10) and FGD in the COHPAC configuration. Two different bag fabrics were installed in the baghouse compartments of the PoCT, one was a 2.7 denier PPS (Ryton) felt and the other was a 7.0 denier PPS felt Torcon. The Torcon bag is a high permeability fabric designed to retain more dust cake an operate at a lower pressure drop that a standard 2.7-denier Ryton felt bag. The longer-term injection tests were conducted for 48 hours at a targeted injection rate of $2 \mathrm{lb} / \mathrm{Mmacf}$ and a temperature of $315^{\circ} \mathrm{F}$. The mercury removal across the baghouse increased for approximately 2 to 12 hours before leveling off. Both the CFA and A10 reached the percent mercury removal observed in the parametric evaluations within 1 hour of injection. The FGD reached similar results but only after 12 hours of injection. The percent mercury removal for all sorbents ranged from $94 \%$ to $99 \%$.

By-products collected in each baghouse hopper were sent to the URS Group for byproduct evaluations. Results are presented later in the report.

\subsubsection{P4 Unit 1Parametric Results}

Following the screening evaluations on Unit 1, the performance of the three novel sorbents (AMS, A6, and CR325D) and FGD were characterized at various batch injection rates and at two operating gas temperatures $\left(280^{\circ} \mathrm{F}\right.$ and $\left.350^{\circ} \mathrm{F}\right)$. The mercury removal results for each sorbent at the two gas temperatures are shown in Figure 8. As shown, 
both the A6 and CR325D performed slightly better than the baseline sorbent FGD. The AMS did not perform as well as the carbon-based sorbents. The impact of increasing the gas temperature from $280^{\circ} \mathrm{F}$ to $350^{\circ} \mathrm{F}$ decreased the mercury removal performance for all sorbents. The greatest difference was seen at the lower injection rates.

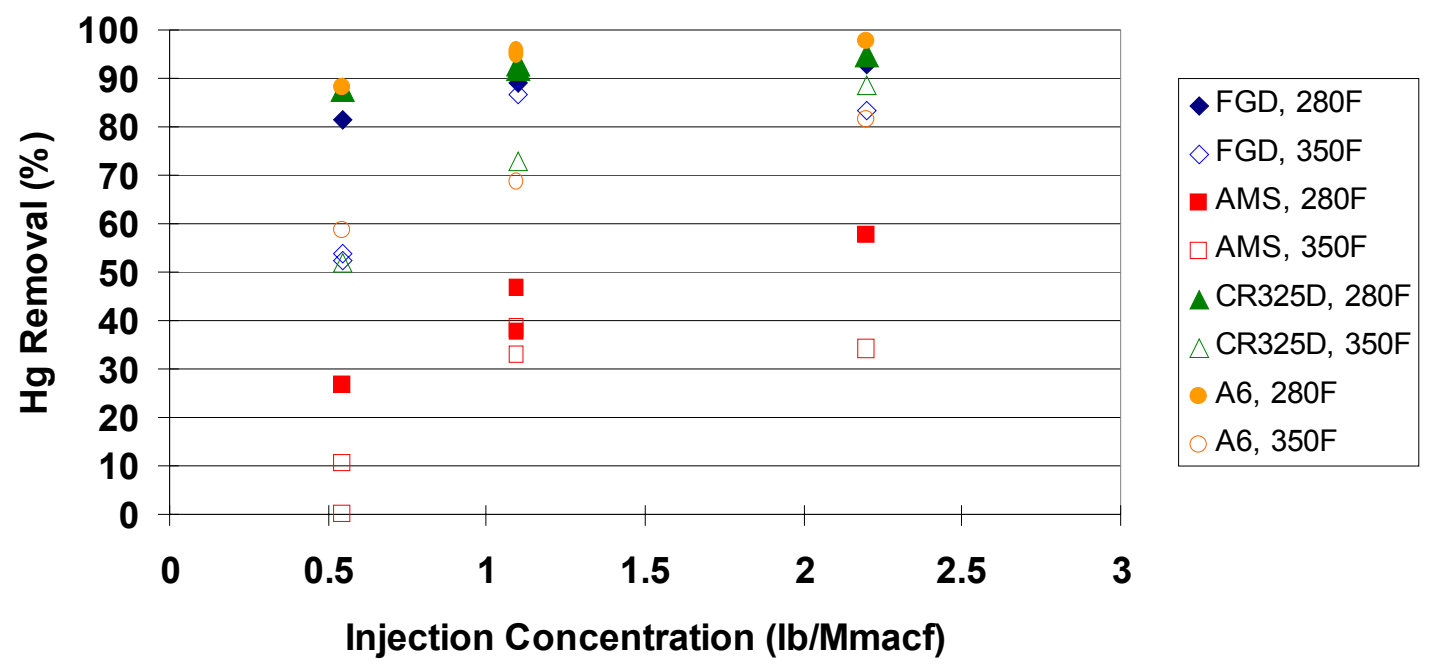

Figure 8. Mercury sorbent parametric evaluations on Unit 1 at P4.

\subsubsection{P4 Unit 2 Parametric Results}

Three mercury sorbents (AMS, A6, and CR325D) and the baseline sorbent FGD were evaluated on Unit 2 at various sorbent batch injection rates and two gas temperatures $\left(300^{\circ} \mathrm{F}\right.$ to $\left.350^{\circ} \mathrm{F}\right)$. During the first evaluation period (December 5-9, 2003), the SCR catalyst was in place in Unit 2 but the ammonia flow was not activated. The second evaluation period occurred when the SCR was working as designed (January 14-22, 2004). As shown in Figure 9, the mercury removal decreased slightly for AMS and FGD when the SCR was online and the A6 and CR325D performed similarly under the two conditions. The open symbols represent the conditions when the SCR was offline.

Three additional sorbents (Thief, IAC, and CFA) were evaluated on Unit 2 at a gas temperature of $300^{\circ} \mathrm{F}$ and the results are shown in Figure 10. The performance at 0.5 $\mathrm{lb} /$ Mmacf ranged from $49 \%$ (Thief) to $66 \%$ (CFA) mercury removal.

Sorbent performance degraded slightly for the carbon-based sorbents with an increase in gas temperature from $300^{\circ} \mathrm{F}$ and $350^{\circ} \mathrm{F}$. At a batch injection rate of $2.2 \mathrm{lb} / \mathrm{Mmacf}$, the carbon-based sorbents performed similarly, with a mercury removal of $83 \%$ to $86 \%$, as seen in Figure 11. The AMS mercury removal actually increased slightly at the higher injection rate and temperature. 




Figure 9. Parametric sorbent evaluations on P4's Unit 2 with and without SCR on line at a gas temperature of $300^{\circ} \mathrm{F}$. Repeated data shown where available for individual sorbents.

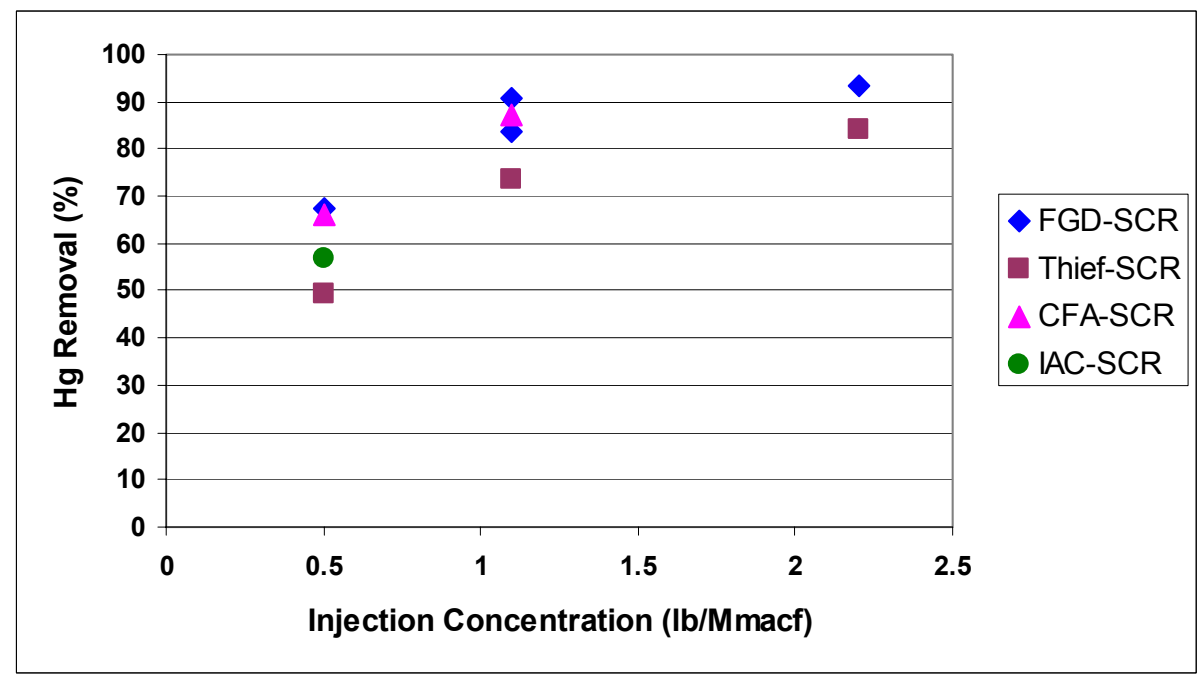

Figure 10. Parametric sorbent evaluations on P4's Unit 2 with SCR on line at a gas temperature of $300^{\circ} \mathrm{F}$. 


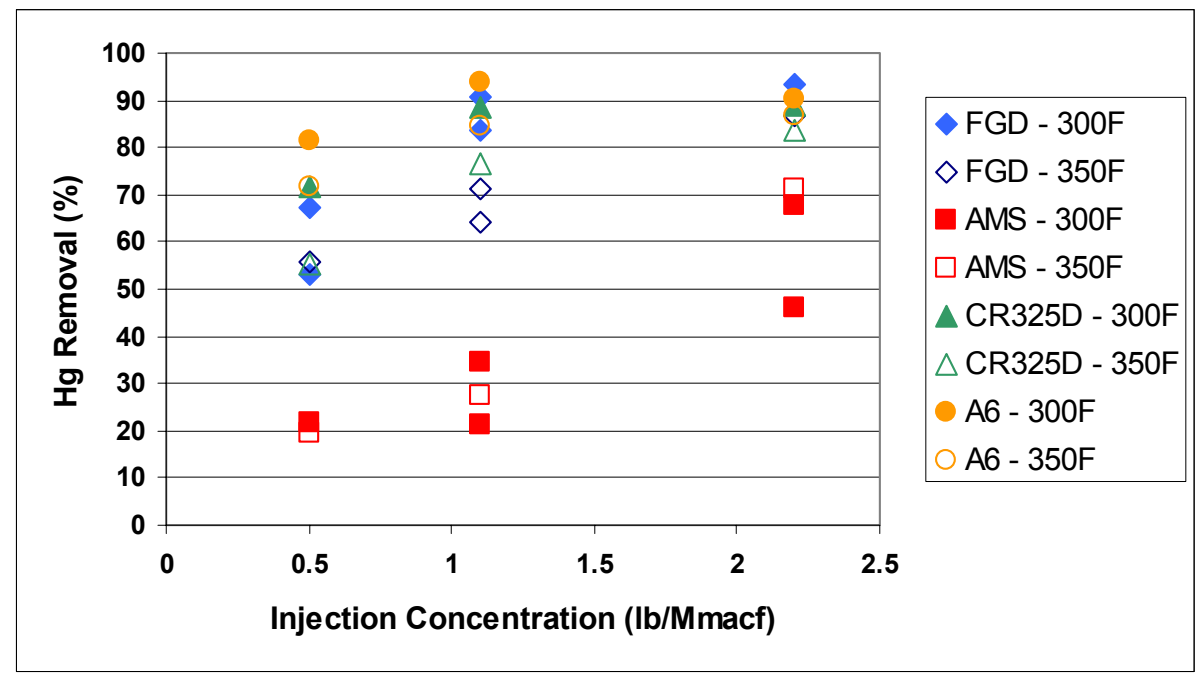

Figure 11. Parametric sorbent evaluations on P4's Unit 2 with SCR on line at two gas temperatures. Repeated data shown where available for individual sorbents.

\subsection{By-product Results}

During the long-term sorbent evaluations at Powerton and VAPP, by-product samples were collected in the baghouse hoppers for each sorbent evaluated. At Powerton, FGD, $\mathrm{HOK}$, and CFA sorbents were evaluated long-term while at VAPP, FGD, A10, and CFA sorbents were evaluated. The term "by-product" is defined as fly ash and spent sorbent for this project. The results from the mercury analyses of the by-products, the simulated landfill tests, the leaching tests, and desorption tests are presented below.

\subsubsection{Mercury Analyses on By-product Samples}

Results from the mercury analysis of the Powerton and VAPP by-product samples are presented in Table 6 and Table 7, respectively. 
Table 6. Powerton By-product Sample Mercury Concentration and LOI Data Summary.

\begin{tabular}{|l|c|c|c|}
\hline \multicolumn{1}{|c|}{ Sample ID } & $\begin{array}{c}\text { Frontier } \\
\text { Geosciences, } \\
\mu \mathbf{g} / \mathbf{g}\end{array}$ & $\begin{array}{c}\text { URS } \\
\text { Corporation, } \\
\boldsymbol{\mu} \mathbf{g} / \mathbf{g}\end{array}$ & \% LOI \\
\hline \hline Powerton Baseline Ash & - & 1.34 & 3.31 \\
\hline FGD 6/22-6/23/02 - bag 1 & 5.53 & 5.48 & 5.78 \\
\hline FGD 6/22-6/23/02 - bag 2 & - & 5.99 & 6.33 \\
\hline HOK 6/28/02 - bag 1 & 8.73 & 11.70 & 7.15 \\
\hline HOK 6/28/02 - bag 2 & - & 15.26 & 11.98 \\
\hline CFA 6/30-7/1/02 - bag 1 & 9.3 & 10.13 & 15.24 \\
\hline CFA 6/30-7/1/02 - bag 2 & - & 8.55 & 20.61 \\
\hline
\end{tabular}

* Note: bag 1 is a Teflon coated fiberglass bag and bag 2 is a 7.0-denier Torcon felt bag.

Table 7. VAPP By-product Sample Mercury Concentration and LOI Data Summary.

\begin{tabular}{|l|c|c|}
\hline \multicolumn{1}{|c|}{ Sample ID } & $\begin{array}{c}\text { URS } \\
\text { Corporation, } \\
\mu \mathbf{\mu} / \mathbf{g ~ H g}\end{array}$ & \% LOI \\
\hline \hline VAPP Baseline Ash & 1.04 & 22.20 \\
\hline CFA 3/27/03 - bag 1 & 2.25 & 27.57 \\
\hline CFA 3/27/03 - bag 2 & 1.47 & 30.49 \\
\hline A10 4/3/03 - bag 1 & 1.23 & 25.85 \\
\hline A10 4/3/03 - bag 2 & 1.59 & 27.22 \\
\hline FGD 3/21/03- bag 1 & 0.80 & 28.17 \\
\hline FGD 3/21/03 - bag 2 & 1.16 & 29.96 \\
\hline
\end{tabular}

* Note: bag 1 is a 2.7-denier Ryton bag and bag 2 is a 7.0-denier Torcon felt bag.

As can be seen in Table 6, the two independent mercury concentration measurements for the Powerton by-product samples show relatively good agreement given typical variability from sample aliquot to sample aliquot.

The $\%$ LOI of the by-product samples from both sites increased with the addition of sorbent. The mercury concentration of the Powerton by-product samples increased substantially whereas the mercury concentration in the VAPP by-product samples did not show a major uptake of mercury for most samples.

The trend of increasing mercury concentration with increasing LOI, due to sorbent injection, was observed in the Powerton by-product samples containing the FGD sorbent and the HOK sorbent. However, this trend was not observed in the Powerton by-product sample containing the CFA sorbent. Although the CFA bag 1 sample did show higher 
mercury concentrations than in the baseline ash, the bag 2 sample with the higher LOI showed less mercury content than the bag 1 sample at lower LOI (even after considering dilution by the sorbent added). The VAPP by-product samples showed considerably lower mercury concentrations than the Powerton by-products in spite of considerably higher LOI content which could be attributable to the lower in-duct vapor-phase mercury concentrations observed at VAPP. Although the long-term test samples all showed higher LOI content than the baseline sample, not all contained higher than baseline mercury concentrations.

\subsubsection{Landfill Simulation Tests}

Tables 8 and 9 summarize the results of the Powerton by-product sample landfill simulation tests, which were conducted with the by-product samples collected from baghouse 2 (Torcon). Tables 10 and 11 summarize the results of the VAPP by-product samples landfill simulation tests, which were conducted with the by-product samples collected from baghouse 1 (2.7-denier Ryton).

In each table, the initial ng of mercury available for desorption in the sample used is shown, followed by the mercury mass gain in the downstream Carulite mercury adsorption tubes after each measurement interval.

Table 8. Results of Powerton Room Temperature Landfill Simulation Tests.

\begin{tabular}{|c|c|c|c|c|c|c|c|c|}
\hline \multirow[b]{2}{*}{ Sample ID } & \multirow{2}{*}{$\begin{array}{c}\text { Available } \\
\text { Hg for } \\
\text { desorption } \\
\text { (ng) }\end{array}$} & \multicolumn{6}{|c|}{ Carulite Tube $\mathbf{H g}$ Gain, ng of $\mathbf{H g}$} & \multirow[b]{2}{*}{$\begin{array}{l}\% \mathrm{Hg} \\
\text { Loss }\end{array}$} \\
\hline & & $\begin{array}{c}2 \\
\text { weeks }\end{array}$ & $\begin{array}{c}8 \\
\text { weeks }\end{array}$ & $\begin{array}{c}14 \\
\text { weeks }\end{array}$ & \begin{tabular}{|c|}
18 \\
weeks
\end{tabular} & $\begin{array}{c}24 \\
\text { weeks }\end{array}$ & $\begin{array}{l}\text { Total } \\
\text { Gain }\end{array}$ & \\
\hline Powerton Baseline Ash & 6,800 & $<11.3$ & $<11.3$ & - & F- & - & $<22.6$ & $<0.33$ \\
\hline $\begin{array}{l}\text { FGD Long Term 6/22- } \\
6 / 23 / 02 \text { - bag } 2\end{array}$ & 28,500 & $<11.3$ & $<11.3$ & - & - & - & $<22.6$ & $<0.08$ \\
\hline HOK 6/28/02-bag 2 & 79,400 & $<11.3$ & $<11.3$ & - & - & - & $<22.6$ & $<0.05$ \\
\hline CFA $6 / 30-7 / 1 / 02-$ bag 2 & 42,800 & $<11.3$ & $<11.3$ & - & - & - & $<22.6$ & $<0.03$ \\
\hline
\end{tabular}


Table 9. Results of Powerton $140^{\circ}$ F Landfill Simulation Tests.

\begin{tabular}{|c|c|c|c|c|c|c|c|c|}
\hline \multirow[b]{2}{*}{ Sample ID } & \multirow{2}{*}{$\begin{array}{c}\text { Available } \\
\text { Hg for } \\
\text { desorption } \\
\text { (ng) }\end{array}$} & \multicolumn{6}{|c|}{ Carulite Tube Hg Gain, ng of $\mathrm{Hg}$} & \multirow[b]{2}{*}{$\begin{array}{l}\% H g \\
\text { Loss }\end{array}$} \\
\hline & & $\begin{array}{c}2 \\
\text { weeks }\end{array}$ & $\begin{array}{c}8 \\
\text { weeks }\end{array}$ & $\begin{array}{c}14 \\
\text { weeks }\end{array}$ & $\begin{array}{c}18 \\
\text { weeks }\end{array}$ & $\begin{array}{c}24 \\
\text { weeks }\end{array}$ & $\begin{array}{l}\text { Total } \\
\text { Gain }\end{array}$ & \\
\hline Powerton Baseline Ash & 6,700 & $<11.3$ & $<11.3$ & $<11.3$ & $<11.3$ & $<11.3$ & $<56.3$ & $<1.01$ \\
\hline $\begin{array}{l}\text { FGD Long Term 6/22- } \\
6 / 23 / 02 \text { - bag } 2\end{array}$ & 29,950 & $<11.3$ & $<11.3$ & $<11.3$ & $<11.3$ & $<11.3$ & $<56.3$ & $<0.23$ \\
\hline HOK 6/28/02 - bag 2 & 76,300 & $<11.3$ & $<11.3$ & $<11.3$ & $<11.3$ & $<11.3$ & $<56.3$ & $<0.09$ \\
\hline CFA 6/30-7/1/02 - bag 2 & 42,750 & $<11.3$ & $<11.3$ & $<11.3$ & $<11.3$ & $<11.3$ & $<56.3$ & $<0.16$ \\
\hline
\end{tabular}

Table 10. Results of VAPP Room Temperature Landfill Simulation Tests.

\begin{tabular}{|c|c|c|c|c|c|c|c|}
\hline \multirow[b]{2}{*}{ Sample ID } & \multirow{2}{*}{$\begin{array}{c}\text { Available } \\
\text { Hg for } \\
\text { desorption } \\
\text { (ng) }\end{array}$} & \multicolumn{5}{|c|}{$\begin{array}{c}\text { Carulite Tube Hg Gain, ng of } \\
\text { Hg }\end{array}$} & \multirow[b]{2}{*}{$\%$ Hg Loss } \\
\hline & & $\begin{array}{c}2 \\
\text { weeks }\end{array}$ & $\begin{array}{c}8 \\
\text { weeks }\end{array}$ & $\begin{array}{c}14 \\
\text { weeks }\end{array}$ & $\begin{array}{c}18 \\
\text { weeks }\end{array}$ & $\begin{array}{l}\text { Total } \\
\text { Gain }\end{array}$ & \\
\hline $\begin{array}{l}\text { Baseline VAPP Ash } \\
3 / 21 / 03\end{array}$ & 4,163 & $<13.2$ & $<13.2$ & $<13.2$ & $<13.2$ & $<53.0$ & $<1.3$ \\
\hline FGD 3/21/03 - bag 1 & 3,361 & $<13.2$ & $<13.2$ & $<13.2$ & $<13.2$ & $<53.0$ & $<1.6$ \\
\hline FGD 3/21/03 - bag 1 dup & 3,621 & $<13.2$ & $<13.2$ & $<13.2$ & $<13.2$ & $<53.0$ & $<1.5$ \\
\hline CFA 3/27/03 - bag 1 & 9,667 & $<13.2$ & $<13.2$ & $<13.2$ & $<13.2$ & $<53.0$ & $<0.5$ \\
\hline A10 4/3/03 - bag 1 & 5,489 & $<13.2$ & $<13.2$ & $<13.2$ & $<13.2$ & $<53.0$ & $<1.0$ \\
\hline
\end{tabular}


Table 11. Results of VAPP $140^{\circ}$ F Landfill Simulation Tests.

\begin{tabular}{|c|c|c|c|c|c|c|c|}
\hline \multirow[b]{2}{*}{ Sample ID } & \multirow{2}{*}{$\begin{array}{c}\text { Available } \\
\text { Hg for } \\
\text { desorption } \\
\text { (ng) }\end{array}$} & \multicolumn{5}{|c|}{$\begin{array}{c}\text { Carulite Tube Hg Gain, ng of } \\
\text { Hg }\end{array}$} & \multirow[b]{2}{*}{ \%Hg Loss } \\
\hline & & $\begin{array}{c}2 \\
\text { weeks }\end{array}$ & $\begin{array}{c}8 \\
\text { weeks }\end{array} \mid$ & $\begin{array}{c}14 \\
\text { weeks }\end{array}$ & \begin{tabular}{|c|}
18 \\
weeks
\end{tabular} \mid & $\begin{array}{l}\text { Total } \\
\text { Gain }\end{array}$ & \\
\hline $\begin{array}{l}\text { Baseline VAPP Ash } \\
3 / 21 / 03\end{array}$ & 4,184 & $<13.2$ & $<13.2$ & $<13.2$ & $<13.2$ & $<53.0$ & $<1.3$ \\
\hline FGD 3/21/03 - bag 1 & 3,512 & $<13.2$ & $<13.2$ & $<13.2$ & $<13.2$ & $<53.0$ & $<1.5$ \\
\hline FGD 3/21/03 - bag 1 dup & 3,606 & $<13.2$ & $<13.2$ & $<13.2$ & $<13.2$ & $<53.0$ & $<1.5$ \\
\hline CFA 3/27/03 - bag 1 & 9,898 & $<13.2$ & $<13.2$ & $<13.2$ & $<13.2$ & $<53.0$ & $<0.5$ \\
\hline A10 4/3/03 - bag 1 & 5,535 & $<13.2$ & $<13.2$ & $<13.2$ & $<13.2$ & $<53.0$ & $<1.0$ \\
\hline
\end{tabular}

All of the individual results shown in the Tables 8-11 are "less than" values. These values are considered to be below measurable levels. The minimum measurable value was estimated to be three standard deviations about the mean mercury content of all of the method-blank Carulite tubes analyzed. For the Powerton by-product sample tests, the mean value of the method blanks was $5.2 \mathrm{ng}$ and the standard deviation of the method blanks was $2.0 \mathrm{ng}$, so any mercury gain (or loss) of less than $11.3 \mathrm{ng}$ was considered to be below measurable levels in these tests. The VAPP landfill simulations were run separately from the Powerton landfill simulations; therefore, they have a different set of method blanks and a different detection limit. For the VAPP by-product sample tests, the mean value of the method blanks was $3.1 \mathrm{ng}$ and the standard deviation of the method blanks was $3.4 \mathrm{ng}$, so any mercury gain (or loss) of less than $13.2 \mathrm{ng}$ was considered to be below measurable levels in these tests and treated as a zero value in the summations. No measurable amounts of mercury loss were observed for any of the by-product samples from Powerton or VAPP.

\subsubsection{Leaching Tests}

Results from the leaching tests performed on the Powerton and VAPP by-product samples are presented in Tables 12 and 13, respectively. The leachates produced from the various leaching procedures were analyzed for mercury, and those concentrations were compared to the Maximum Contaminent Level (MCL), which is related to Federal drinking water standards. The MCL criteria for mercury is $0.2 \mathrm{ppm}$, and none of the Powerton or VAPP samples were at the threshold of being considered hazardous by the MCL criteria. Most samples were below analytical detection limits for mercury. 
Table 12. Leaching Results of the Powerton By-product Samples in SPLP Matrix and Water.

\begin{tabular}{|l|c|c|c|}
\hline \multicolumn{1}{|c|}{ Sample ID } & $\begin{array}{c}\text { SPLP } \\
\text { Matrix } \\
\text { pH 2.5 } \\
\mathbf{m g / L ~ H g}\end{array}$ & $\begin{array}{c}\text { SPLP Matrix } \\
\mathbf{p H ~ 5 . 0} \\
\mathbf{m g} / \mathbf{L ~ H g}\end{array}$ & $\begin{array}{c}\text { ASTM type II } \\
\text { Water } \\
\mathbf{p H ~ 7 . 0} \\
\mathbf{m g} / \mathbf{L ~ H g}\end{array}$ \\
\hline Powerton Baseline Ash & $<0.00006$ & $<0.00006$ & $<0.00006$ \\
\hline $\begin{array}{l}\text { FGD Long Term 6/22-6/23/02 } \\
- \text { bag 1 }\end{array}$ & $<0.00006$ & $<0.00006$ & 0.00012 \\
\hline $\begin{array}{l}\text { FGD Long Term 6/22-6/23/02 } \\
- \text { bag 2 }\end{array}$ & $<0.00006$ & $<0.00006$ & 0.00017 \\
\hline HOK 6/28/02 - bag 1 & $<0.00006$ & $<0.00006$ & $<0.00006$ \\
\hline HOK 6/28/02- bag 2 & $<0.00006$ & $<0.00006$ & $<0.00006$ \\
\hline CFA 6/30-7/1/02 - bag 1 & $<0.00006$ & $<0.00006$ & $<0.00006$ \\
\hline CFA 6/30-7/1/02 - bag 2 & $<0.00006$ & $<0.00006$ & $<0.00006$ \\
\hline
\end{tabular}

Table 13. Leaching Results of the VAPP By-product Sample in SPLP Matrix, Water, $0.1 \mathrm{M} \mathrm{Na} \mathrm{CO}_{3}$, and $0.1 \mathrm{~N} \mathrm{H}_{2} \mathrm{SO}_{4}$.

\begin{tabular}{|c|c|c|c|c|}
\hline Sample ID & $\begin{array}{c}\text { SPLP } \\
\text { Matrix } \\
\text { pH 4.2, } \\
\text { mg/L Hg }\end{array}$ & $\begin{array}{c}\text { ASTM Type II } \\
\text { Water } \\
\text { pH 7.0, } \\
\text { mg/L Hg }\end{array}$ & $\begin{array}{c}0.1 \mathrm{M} \\
\mathrm{Na}_{2} \mathrm{CO}_{3} \\
\mathrm{pH}=11.4, \\
\mathrm{mg} / \mathrm{L} \mathrm{Hg}\end{array}$ & $\begin{array}{c}0.1 \mathrm{~N} \mathrm{H}_{2} \mathrm{SO}_{4} \\
\mathrm{pH}=1.3, \\
\mathrm{mg} / \mathrm{L} \mathrm{Hg}\end{array}$ \\
\hline $\begin{array}{l}\text { VAPP Baseline Ash } \\
3 / 21 / 03\end{array}$ & $<0.00012$ & $<0.00010$ & $<0.00025$ & $<0.00015$ \\
\hline FGD $3 / 21 / 03$ - bag 1 & $<0.00012$ & 0.00015 & $<0.00025$ & $<0.00015$ \\
\hline FGD 3/21/03 - bag 2 & $<0.00012$ & $<0.00010$ & $<0.00025$ & $<0.00015$ \\
\hline CFA 3/27/03 - bag 1 & $<0.00012$ & $<0.00010$ & $<0.00025$ & 0.00022 \\
\hline CFA $3 / 27 / 03$ - bag 2 & $<0.00012$ & $<0.00010$ & $<0.00025$ & $<0.00015$ \\
\hline A10 4/3/03 - bag 1 & $<0.00012$ & $<0.00010$ & $<0.00025$ & 0.00026 \\
\hline A10 4/3/03 - bag 2 & $<0.00012$ & 0.00014 & $<0.00025$ & 0.00032 \\
\hline
\end{tabular}




\subsubsection{Desorption Tests}

Table 14 shows the desorption profile of each desorption test performed. The percent of mercury desorbed at each temperature is summarized. The percent desorbed represented in Table 14 was calculated by dividing the ng of mercury desorbed at each temperature by the total amount of available ng of $\mathrm{Hg}$ in the original sample.

Table 14. Powerton By-product Samples Desorption Profile.

\begin{tabular}{|c|c|c|c|c|c|c|c|c|}
\hline Temp & \multicolumn{2}{|c|}{ Base Ash } & \multicolumn{2}{|c|}{ FGD } & \multicolumn{2}{|c|}{ HOK } & \multicolumn{2}{|c|}{ CFA } \\
\hline & $\begin{array}{c}\% \\
\text { desorb }\end{array}$ & $\begin{array}{r}\text { Total \% } \\
\text { desorbed }\end{array}$ & $\begin{array}{c}\% \\
\text { desorb }\end{array}$ & $\begin{array}{c}\text { Total \% } \\
\text { desorbed }\end{array}$ & $\begin{array}{c}\% \\
\text { desorb }\end{array}$ & $\begin{array}{r}\text { Total \% } \\
\text { desorbed }\end{array}$ & $\begin{array}{c}\% \\
\text { desorb } \\
\end{array}$ & $\begin{array}{r}\text { Total \% } \\
\text { desorbed }\end{array}$ \\
\hline $0-150$ & 8.0 & 8.0 & 0.0 & 0.0 & 0.0 & 0.0 & 0.0 & 0.0 \\
\hline 170 & 38.0 & 46.0 & & & & & & \\
\hline 200 & 0.0 & 46.0 & & & & & & \\
\hline 250 & 0.0 & 46.0 & 0.0 & 0.0 & 0.0 & 0.0 & 0.0 & $\begin{array}{c}0.0 \\
(0.0)\end{array}$ \\
\hline 300 & 0.0 & 46.0 & & & & & & \\
\hline 350 & 1.8 & 47.8 & 13.7 & 13.7 & 6.7 & 6.7 & 0.0 & $\begin{array}{c}0.0 \\
(0.0)\end{array}$ \\
\hline 400 & 3.9 & 51.7 & 18.7 & 32.4 & 1.4 & 8.1 & 7.0 & $\begin{array}{c}7.0 \\
(4.4)\end{array}$ \\
\hline 450 & 5.8 & 57.5 & 47.9 & 80.3 & 14.3 & 22.4 & 60.7 & $\begin{array}{c}67.7 \\
(42.8)\end{array}$ \\
\hline 500 & 3.5 & 61.0 & 8.7 & 89.0 & 14.2 & 36.6 & 80.2 & $\begin{array}{l}147.9 \\
(93.5)\end{array}$ \\
\hline 550 & 6.3 & 67.3 & 5.1 & 94.1 & 0.4 & 37.0 & 5.3 & $\begin{array}{l}153.2 \\
(96.8)\end{array}$ \\
\hline 600 & 0.5 & 67.8 & 3.5 & 97.6 & 2.4 & 39.4 & 2.7 & $\begin{array}{l}155.9 \\
(98.5)\end{array}$ \\
\hline 650 & & & 1.4 & 99.0 & 0.7 & 40.1 & 2.3 & $\begin{array}{l}158.2 \\
(99.9)\end{array}$ \\
\hline 700 & 1.1 & 68.9 & 0.6 & 99.6 & 0.0 & 40.1 & 0.0 & $\begin{array}{l}158.2 \\
(99.9)\end{array}$ \\
\hline
\end{tabular}

The by-product samples containing sorbents lost mercury at higher temperatures than Powerton's baseline ash. The baseline ash sample lost $46 \%$ of its original mercury content by $200^{\circ} \mathrm{F}$, while the samples containing sorbent did not lose any mercury up to 
$200^{\circ} \mathrm{F}$. This suggests that sorbent-containing by-product mixtures will be less susceptible to mercury losses at high ambient temperatures. The by-product samples containing sorbents did desorb an appreciable amount of mercury as the temperature was increased. By-product samples containing FGD or CFA lost approximately $90 \%$ of the mercury during these evaluations by $500^{\circ} \mathrm{F}$.

The only sample that saw all of the available mercury desorb was from the FGD byproduct. The baseline and HOK by-product only desorbed $69 \%$ and $40 \%$, respectively. The CFA by-product measured $158 \%$ of the original mercury content having been desorbed. It is not clear as to why the CFA sample saw greater than $100 \%$ desorption. This could have been due to a low bias in the measured mercury content of the sample tested, or problems in measuring and/or calculating mercury recoveries during this particular desorption test. Because the total amount of mercury recovered during the desorption test was greater than $100 \%$ of the original content, the second number was added in parentheses showing "normalized" mercury desorption percentages which were calculated assuming that $100 \%$ of the mercury in the original sample was recovered during the test.

VAPP by-product samples were not evaluated due to equipment and time constraints. Duplicate evaluations on the Powerton by-product samples would have been desirable to measure the repeatability of the desorption percentages, particularly for the CFA samples. Sand blank tests were run, and all saw no measurable mercury desorption.

These results suggest that the FGD and CFA sorbents could possibly be regenerated, since both showed high percentage mercury desorption. The HOK sorbent looked less likely to be regenerable.

\subsection{Economic Analyses}

Dr. Massoud Rostam-Abadi with the Illinois State Geological Survey performed an engineering economic analysis to estimate the production costs of the most promising novel sorbents. An independent contractor reviewed and critically assessed the cost estimates.

There are various ways to examine sorbent costs. A bottom-up buildup of the cost of production for a given quantity, followed by adding overhead/administrative costs and an estimated profit margin, is one approach. This type of buildup is extremely sensitive to the assumptions made both technically and commercially. For the novel sorbents evaluated here, primarily CS80 and CFA, critical assumptions include the source of material supply, site location, and quantity of carbon product demanded. In the pricing provided herein, these assumptions are described in some more detail, and their relevance to the market discussed.

Another important parameter when examining projected costs is the competing prices and commercial offerings available in the marketplace. This puts the sorbent's price into context. This of course is difficult without having insight into competing sorbent 
manufacturers' businesses. Projected future prices of the competition are speculative. An important point to note relative to these prices is that the current market is one in which supply capacity exceeds demand. The beginning of use of carbon-based sorbents for mercury control on coal-fired power plants will change this situation. Buyers will find themselves in a weak position, with demand outstripping supply capacity. This will most likely drive sorbent prices up until supply catches up.

Three sorbents are priced in detail in this exercise. One is a biomass-based sorbent, the second is an oil-based sorbent, and the third is a lignite-based activated carbon. Each price provided is FOB point of manufacture, and assumes a small business centered around production, with minimal staffing. This is a niche application for carbon-based sorbents, since it does not address a larger market that will demand large supply quantities or backing by a large corporation that can absolutely guarantee supply reliability and quality control.

Items included in the pricing are:

- Basic production cost, including raw materials and the variable costs of manufacture (labor, power, consumables, etc);

- Marketing costs are minimal because of the captive market assumed in these scenarios; when they are included they are $1.5 \%-4.5 \%$ of basic production cost;

- General \& Administrative cost at about 5\% of basic production cost;

- Capital recovery, at an interest rate of $6 \%$;

- Reasonable profit.

What is not included is a large corporation that supports marketing, research and development, and ongoing expansion efforts.

\section{Lignite Activated Carbon (LAC)}

For comparison purposes, pricing for LAC was calculated using the same methodology as for the novel sorbents. The LAC pricing assumes that 4.5 power plants of 1,000 MW rating are supplied (quantity is based on $5 \mathrm{lb} / \mathrm{Mmacf}$ carbon). Ten-year financing is used, and the largest practical kiln sizes are employed. At a mine mouth location, 12,500 ton $/ \mathrm{yr}$ of LAC can be supplied for under $\$ 5,000,000$, or less than $\$ 0.20 / \mathrm{lb}$.

This LAC approach could supply a handful of power plants located adjacent to mines, and still may be competitive if shipped within a region. The pricing is significantly lower than current commercial pricing. This is attributable to assuming a small, captive market, appropriate location of the end-user, and simplified processing to obtain the minimum surface area appropriate for the user application of dry sorbent injection for mercury control. In addition, current coal pricing is assumed. This raw material cost is subject to the variability of the coal market. 


\section{CS80}

The CS80 pricing is calculated for two supply scenarios. The first assumes that one power plant of 1,000 MW rating is supplied (quantity is based on $5 \mathrm{lb} / \mathrm{Mmacf}$ carbon) via an on-site, dedicated processing facility. Sixteen-year financing is used. For this example, 2,800 ton/yr of CS 80 could be supplied for about $10 \%$ less per pound than LAC.

The second scenario for CS80 is for a larger supply; 10.7 power plants of 1,000 MW rated capacity. In this case, an existing CS80 plant's facilities are expanded to generate the new supply. With the simplified permitting process and economy of scale, this quantity can be supplied at about $30 \%$ less per pound than LAC.

\section{CFA}

The CFA pricing is for 7.9 power plants of 1,000 MW rating. Ten-year financing is used. It is assumed that 22,000 ton/yr of CFA could be supplied for under $\$ 11,000,000$, or less than $\$ 0.25$ per pound.

The biomass material required for CFA manufacture has limited supply, and may not be widely expandable. Further optimization of the processing of this material may reduce the variable costs.

Table 15 shows current commercial pricing and compares it with pricing for the novel sorbents described here.

Table 15. Sorbent Pricing Comparison.

\begin{tabular}{|l|c|c|}
\hline \multicolumn{1}{|c|}{ Sorbent Description } & Quantity & Price Range, \$/lb \\
\hline $\begin{array}{l}\text { Commercial Powdered } \\
\text { Activated Carbons today }\end{array}$ & $\begin{array}{c}\text { Supersack size or greater } \\
(\geq 900 \mathrm{lb})\end{array}$ & $0.30-0.45$ \\
\hline $\begin{array}{l}\text { LAC: small quantity, } \\
\text { captive supply }\end{array}$ & $12,500 \mathrm{ton} / \mathrm{yr}$ & $<0.20$ \\
\hline CS80 & $2,800 \mathrm{ton} / \mathrm{yr}$ & $<0.18$ \\
& $30,000 \mathrm{ton} / \mathrm{yr}$ & $<0.15$ \\
\hline CFA & $22,000 \mathrm{ton} / \mathrm{yr}$ & $<0.25$ \\
\hline
\end{tabular}

The costs in Table 15 show that mercury control sorbent costs are likely to come down in a competitive marketplace. Although larger companies with more marketing infrastructure, reliability, and negotiating power will supply a large share of the sorbent market, smaller enterprises certainly have the opportunity to provide a lower price to their customers under the right set of circumstances. 


\subsection{Conclusions}

Numerous novel sorbents (5 at Powerton, 17 at VAPP, and 19 at P4) were evaluated for use in mercury control technologies involving sorbent injection. The baseline sorbent was FGD and was evaluated at the three sites. The performance screening results of FGD and five other sorbents evaluated at two or more sites are presented in Figure 12. The performance of the sorbents and FGD did not vary much between the three sites (within $10 \%$ with comparable injection rates). The sorbent screening parameters for each site were presented earlier.

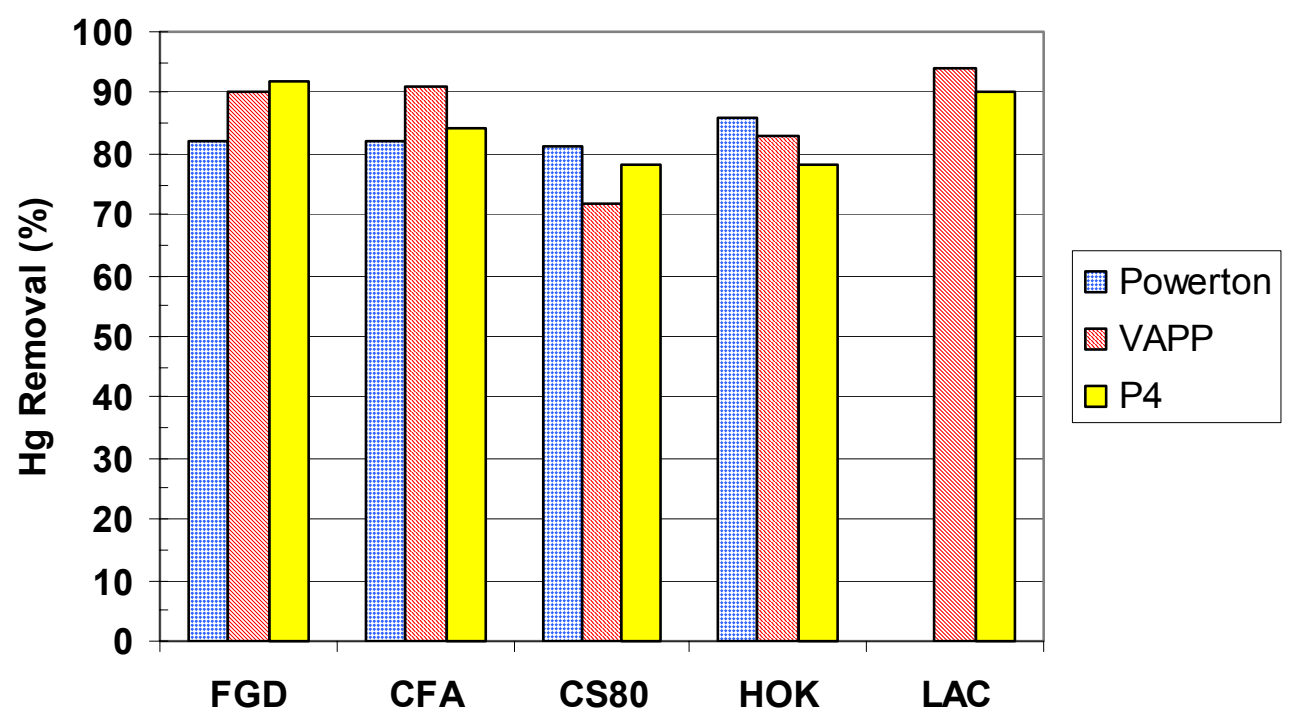

Figure 12. Sorbent comparison for mercury removal at the three test sites.

The best performing sorbents were carbon-based as demonstrated at the three field locations. Performance of the carbon-based sorbents varied and the mercury removal could not be correlated to the amount of modification (i.e. activation or treatment) performed on the base sorbent. Specialty carbons, such as IAC, were included in the program since they have demonstrated enhanced performance at unquie plant sites. Their performance (lower injection concentrations required in some cases) may offset the higher up front cost $(\$ 7 / \mathrm{lb})$, which may provide an economic advantage with specific coals and plant operations. Please note the results for the IAC screening were at injection concentrations much less than that of the other sorbents during screening. For the IAC, the injection concentrations were $0.6,1.7$, and $0.5 \mathrm{lb} / \mathrm{Mmacf}$ for Powerton, VAPP, and P4, respectively.

Non carbon-based sorbents (i.e. AMS and Thief) although not as effective as the carbonbased sorbents tested, may have an economic benefit where by-product resale/utilization 
is an economic consideration. This program did not attempt to validate claims by the sorbent suppliers as to their impact on fly ash reuse. Performance of the sorbents grouped in the "other" category varied depending on the base material (flyash, zeolite, other). The zeolite-based sorbents performed better than the fly ash-based sorbents during sorbent screening at VAPP and P4. Both the Thief and AMS sorbents removed greater than $60 \%$ of the incoming mercury in the TOXECON configuration at P4.

Temperature of the flue gas did not significantly affect sorbent performance in the COHPAC or residence chamber configurations at Powerton. At VAPP, mercury removal increased slightly at the higher temperature $\left(315^{\circ} \mathrm{F}\right.$ to $\left.350^{\circ} \mathrm{F}\right)$ for all three sorbents evaluated in the COHPAC configuration but not in the residence chamber configuration. In addition, sorbent performance increased with increased residence time and injection concentration at both VAPP and Powerton. At P4, the impact of increasing the gas temperature from $280^{\circ} \mathrm{F}$ to $350^{\circ} \mathrm{F}$ decreased the mercury removal performance for all sorbents evaluated. The greatest difference was seen at the lower injection rates. Other plant characteristics may influence sorbent performance and the effect of temperature had on sorbent performance may not be universal to all plants burning similar coals as demonstrated in this program.

Re-injection of sorbent/by-product was evaluated at Powerton using the HOK sorbent and demonstrated $53 \%$ mercury removal compared to $83 \%$ mercury removal with fresh sorbent. Depending on the plant conditions, costs, and mercury removal required, this could be an option for reducing mercury sorbent injection control costs.

Results of the by-product analysis demonstrated that no mercury was released during the air stability or leaching evaluations.

Sorbent economics will be driven by the supply and demand. If there are viable resources located within close proxcimaty of coal-fired utilities, then lower cost options may be available on a case by case basis. Price of the sorbent will also depend on the required mercury reduction needed by the individual utilities. With the information presented on the two coal types, there are a wide range of sorbents that could be made available to satify utilities that require $30 \%$ to $70 \%$ mercury removal when using a similar particulate control scenerio. Other plant issues also need to be addressed when considering sorbent injection with the impact on the sale of by-products being at the top of the list. A sorbent's overall economic impact needs to be taken into account when considering the control technology and cost of mercury control. Again, the overall cost of the sorbents evaluated during this program were not independly verified. Although larger companies with more marketing infrastructure, reliability, and negotiating power will supply a large share of the sorbent market, smaller enterprises certainly have the opportunity to provide a lower price to their customers under the right set of circumstances. 


\section{Appendix A. Description of Mercury Monitors and Sampling Procedures}

\section{A.1 Description of Mercury Monitor}

A semi-continuous mercury emissions monitor (S-CEM) was used during this program to provide near real-time feedback during baseline, screening, and long-term testing. Continuous measurement of mercury at the inlet and outlet of the particulate collector is considered a critical component of a field mercury control program where mercury levels fluctuate with boiler operation (temperature, load, etc.) and decisions must be made concerning parameters such as sorbent feed rate and cooling. The analyzer used for these tests consisted of a cold vapor atomic absorption spectrometer (CVAAS) coupled with a gold amalgamation system (Au-CVAAS). The system is calibrated using vapor-phase elemental mercury. A sketch of the system is shown in Figure A-1. The S-CEM was configured to automatically switch from measuring total vapor-phase mercury to vaporphase elemental mercury during these tests. A photograph of the S-CEM installed at a field site is shown in Figure A-2.

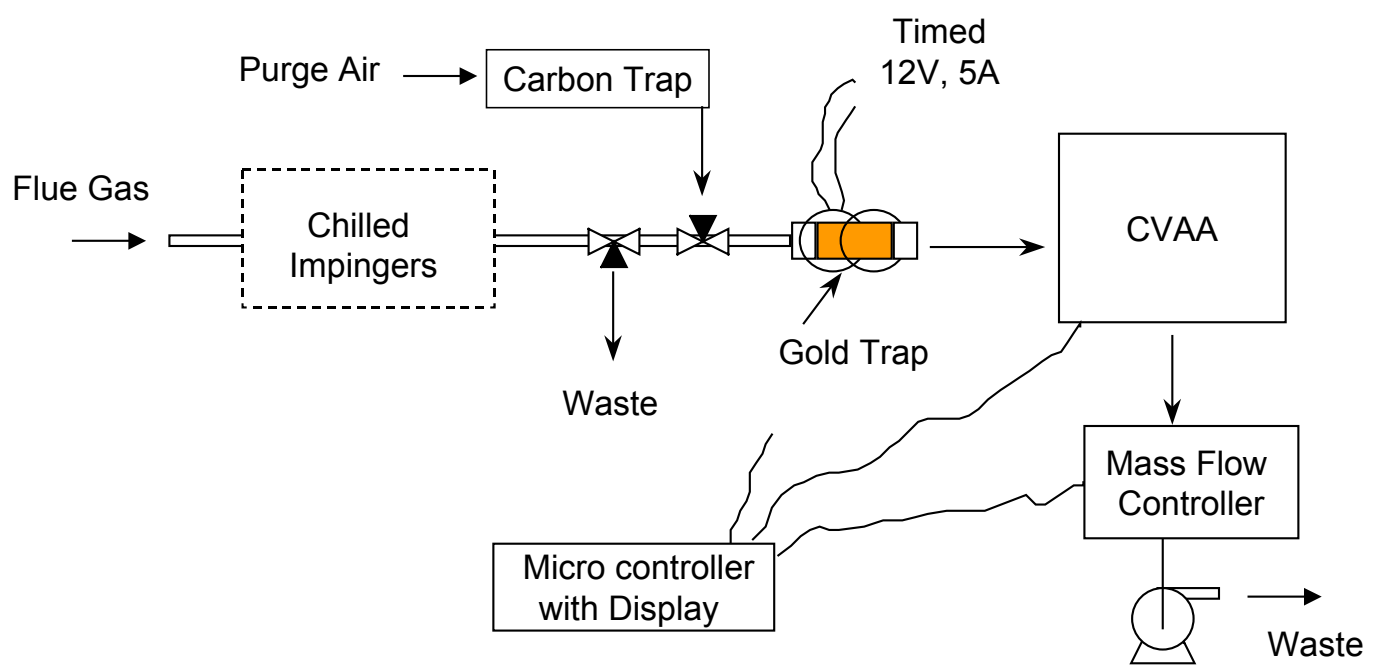

Figure A-1. Sketch of mercury measurement system. 


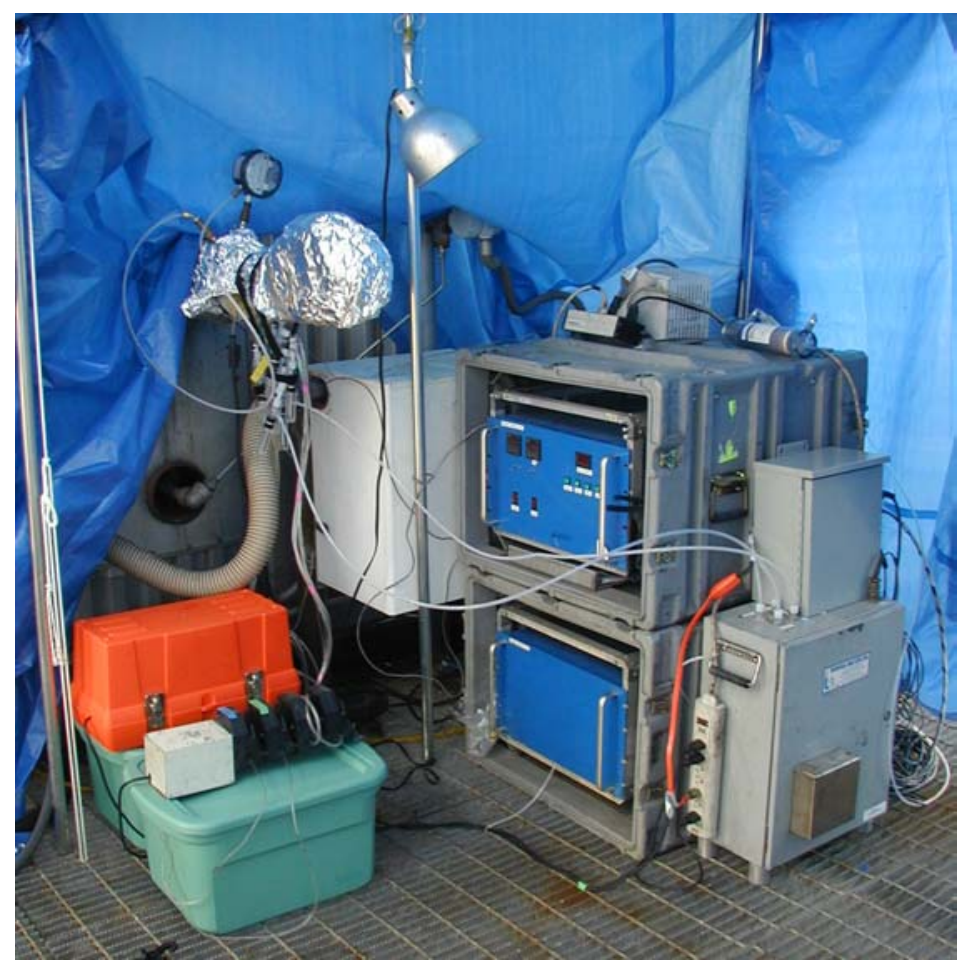

Figure A-2. Photograph of Apogee mercury S-CEM installed at a field site.

Although it is very difficult to transport non-elemental mercury in sampling lines, elemental mercury can be transported without significant problems. Since the AuCVAAS measures mercury by using the distinct lines of the UV absorption characteristic of $\mathrm{Hg}^{0}$, the non-elemental fraction is either converted to elemental mercury (for total mercury measurement) or removed (for measurement of the elemental fraction) near the sample extraction point. This minimizes any losses due to the sampling system.

For total vapor-phase mercury measurements, all non-elemental vapor-phase mercury in the flue gas must be converted to elemental mercury. A reduction solution of stannous chloride in hydrochloric acid is used to convert $\mathrm{Hg}^{2+}$ to $\mathrm{Hg}^{0}$. The solution is mixed as prescribed in the draft Ontario Hydro Method for Manual Mercury Measurements. To measure speciated mercury, an impinger of potassium chloride $(\mathrm{KCl})$ solution mixed as prescribed by the draft Ontario Hydro Method replaces the stannous chloride solution to capture oxidized mercury. The impinger solutions are continuously refreshed to assure continuous exposure of the gas to active chemicals.

\section{A.2 Sampling Procedures and QA/QC}

During testing, the analyzer sampling time is set to collect nominally 20 ng of mercury per sampling cycle. The noise level of the analyzer operating at a field site is approximately $1 \mathrm{ng}$, thus collecting $20 \mathrm{ng}$ provides a signal-to-noise ratio of 20. 
The mercury monitor is calibrated following installation at the field site for mercury, sample flow rate, and oxygen concentration. The calibration of both the Au-CVAA analyzer, which measures the mass of mercury desorbed, and the mass flow controller in the monitor, which measures the total sample volume through the analyzer, is checked daily during testing. The analyzer is calibrated by introducing a spike of vapor-phase elemental mercury into the analyzer upstream of the gold wire. The mercury vapor for the spike is drawn from the air space in a vial containing liquid elemental mercury. The mercury spike concentration is calculated from the vapor pressure of mercury and the temperature of the vial. The vial temperature is measured with a precision thermistor. Connecting the operating controller in series with a calibrated mass flow controller checks the calibration of the mass flow controller within the S-CEM.

Documentation of analyzer calibration is recorded on calibration data sheets and any system maintenance is recorded in the project notebook. A calibration file for additional equipment, which contains manufacturers' certification of calibration, is maintained by Apogee Scientific.

Data verification of computer calculations is conducted manually on a periodic basis. Any data collected during periods of suspected operational inconsistencies is rejected as questionable data.

\section{$\underline{\text { A.3 Bench Scale Fixed Bed Adsorption Test Device }}$}

Mercury adsorption tests are conducted by measuring the mercury capacity for sorbents in the presence of mercury-laden flue gas. The test apparatus is illustrated in Figure A-3. Sorbents are mixed in a sand diluent prior to being packed in a temperature-controlled, adsorption column $(1.27 \mathrm{~cm} \mathrm{ID)}$. A ratio of $20 \mathrm{mg}$ sorbent to $10 \mathrm{~g}$ of sand is generally used for carbon-based sorbents and zeolites, and $200 \mathrm{mg}$ sorbent to $10 \mathrm{~g}$ of sand was used for fly ashes. These mass-loadings are chosen to achieve reasonable mercury breakthrough times with the respective sorbents. Prior to flue gas exposure, the sorbent fixed-bed is heated to the desired temperature for periods up to one hour. During this time, the flue gas is by-passed directly to the analytical system to determine the "inlet" mercury concentration. Adsorption tests were initiated by flowing flue gas downward through the fixed-bed column at a flow rate near $1 \mathrm{~L} / \mathrm{min}$. Mercury measurements are made with a mercury S-CEM. 


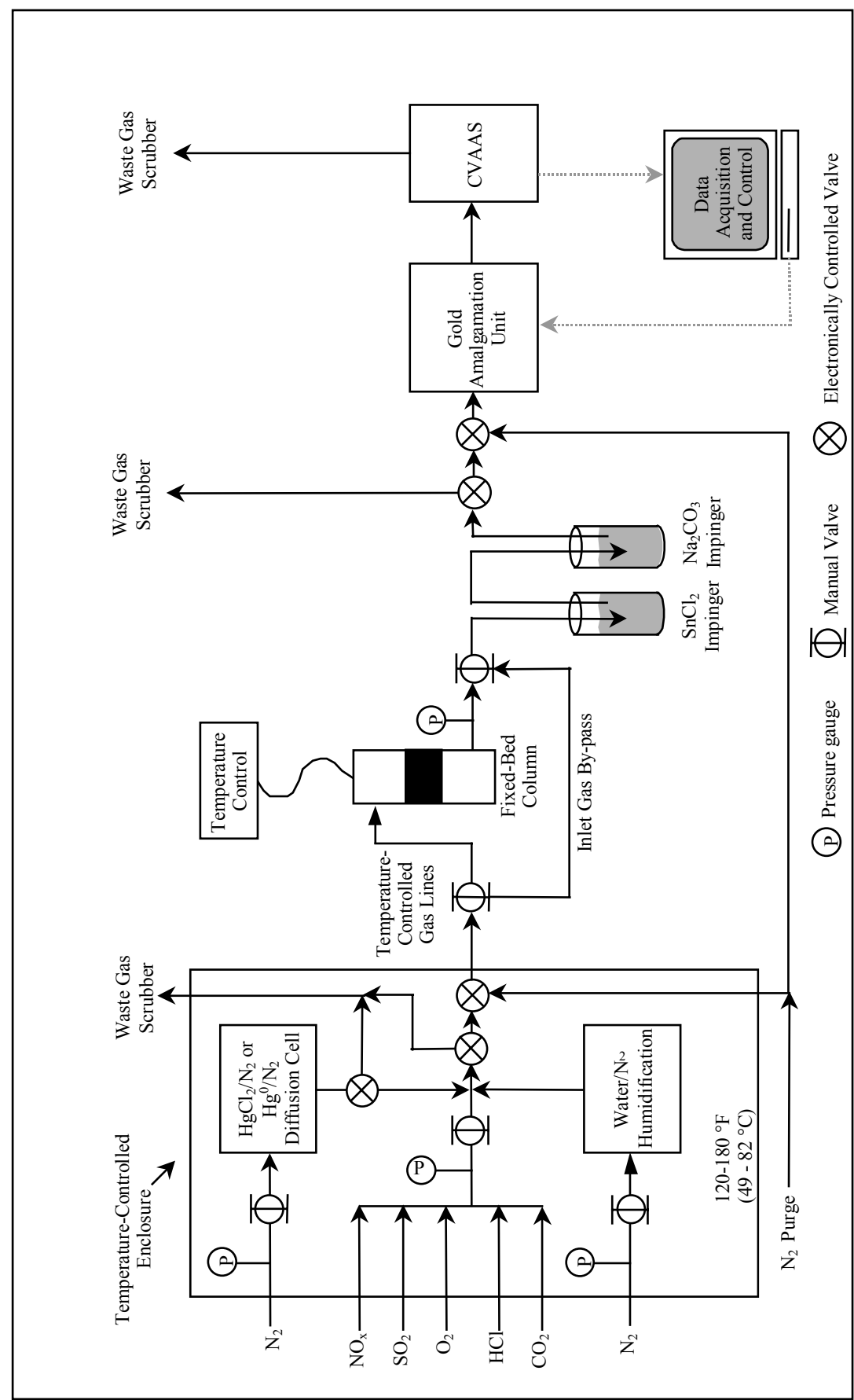

Figure A-3. Bench Scale Fixed Bed Adsorption Test Device.

The amount of mercury exiting the sorbent column is measured on a semi-continuous basis. Gas is passed through the column until $100 \%$ of the inlet mercury is detected at the outlet (100\% breakthrough). The $100 \%$ breakthrough (equilibrium) capacity of the sorbent ( $\mu \mathrm{g} \mathrm{Hg} / \mathrm{g}$ sorbent) is determined by summing the total mercury adsorbed until the time when the outlet mercury concentration is first equal to the inlet concentration. A more detailed description of the adsorption test apparatus can be found elsewhere (8). 


\section{Appendix B. By-Product Equipment and Procedures}

\section{$\underline{\text { B.1 Procedures }}$}

The stability of adsorbed mercury is important to study if the spent fly ash by-products are landfilled or reused. The following studies were intended to investigate whether the adsorbed mercury will be released back to the environment via volatilization or leaching into groundwater. According to the EPA Mercury Report to Congress, some work has been done with ash samples from municipal waste combustors (MWCs) while using carbon injection for mercury removal. The data suggest revolatilization of mercury is minimal.

The fly ash samples generated during this project underwent an air stability test for six months and an aqueous stability test by the EPA 1312 leaching procedure. The purpose of this testing was to simulate conditions the ash by-product may encounter in a landfill environment. The test procedures are described below in more detail.

\section{B.1.1 Air Stability Testing Procedure and Conditions}

The fly ash/sorbent by-product samples resulting from sorbent injection could be disposed of in a landfill. These by-products will contain an increased amount of mercury relative to the baseline fly ash that could potentially release back into the environment via air or water. To evaluate the potential of mercury volatilization, the by-products from the sorbent injection tests underwent a landfill simulation test. Figure B-1 is an illustration of the landfill simulation setup. These tests were conducted by placing a known amount of sample in a closed glass container and exposing that sample to a high flow rate of air for periods ranging from 8 to 24 weeks. The air entered the vessel, contacted the solid, exited the vessel, and passed through a Carulite sorbent tube. Any desorbed mercury exited the glass container with the effluent and passed through the Carulite tube. The air exiting the tube then proceeded into a water bubbler used for flow verification.

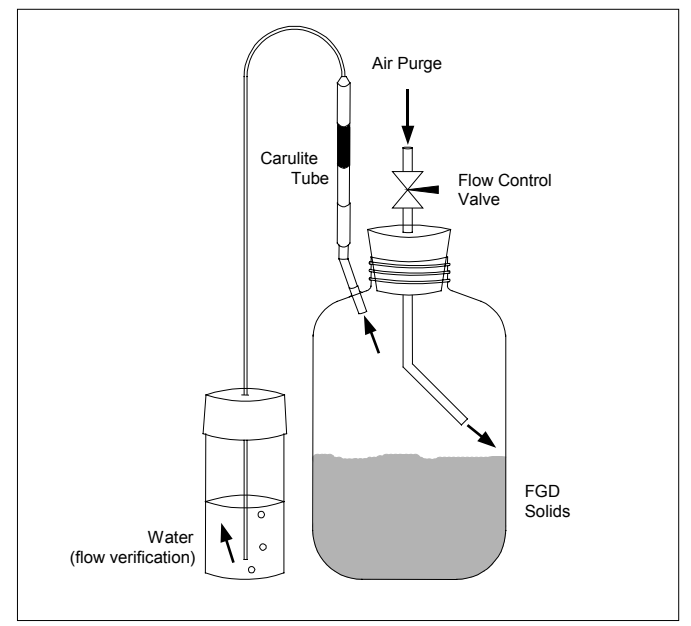

Figure B- 1. Schematic of the Landfill Simulation Test Set Up. 
Carulite is a commercial sorbent, which is composed of greater than $90 \%$ manganese dioxide and is accepted for use in the NIOSH 6009 sampling method to measure mercury in ambient air. All Carulite tubes were packed on site in acid cleaned glass tubes with $0.5000 \mathrm{~g} \pm 0.0010 \mathrm{~g}$ of solid. The Carulite tubes were changed periodically throughout the six-month test period and analyzed for mercury capture. Table B-1 summarizes the nominal time periods over which the Carulite tubes were changed once the test started. Appropriate blank, spike, and duplicates tests were also run.

Table B-1. Landfill Simulation Carulite Change Schedule ( \pm 1 week).

\begin{tabular}{|c|c|c|c|c|c|}
\hline Test Description & Change 1 & Change 2 & Change 3 & Change 4 & Change 5 \\
\hline $\begin{array}{l}\text { Powerton Room } \\
\text { Temp }\end{array}$ & 2 weeks & 6 weeks & $\begin{array}{c}\text { weeks } \\
\text { (stop test) }\end{array}$ & - & - \\
\hline Powerton $140^{\circ} \mathrm{F}$ & 2 weeks & 6 weeks & 12 weeks & 18 weeks & $\begin{array}{r}24 \text { weeks } \\
\text { (stop test) }\end{array}$ \\
\hline VAPP Room Temp & 2 weeks & 6 weeks & 12 weeks & $\begin{array}{c}18 \text { weeks } \\
\text { (stop test) }\end{array}$ & - \\
\hline VAPP $140^{\circ} \mathrm{F}$ & 2 weeks & 6 weeks & 12 weeks & $\begin{array}{r}18 \text { weeks } \\
\text { (stop test) }\end{array}$ & - \\
\hline
\end{tabular}

At the end of the landfill simulation tests, the approximate percent mercury released was calculated by adding the nanograms (ng) of mercury captured on each Carulite tube and dividing this sum by the total ng of mercury in the original sample aliquot available for desorption. Landfill tests were conducted at ambient temperature $\left(\approx 75^{\circ} \mathrm{F}\right)$ and at $140^{\circ} \mathrm{F}$. The higher temperature was meant to represent the highest temperature the byproducts might encounter at high ambient temperature and direct sunlight heating.

The $140^{\circ} \mathrm{F}$ tests were conducted using the schematic illustrated in Figure B-1 except the glass bottles were placed in an oven that was set to maintain that elevated temperature. Figure B-2 is a photograph of the room temperature landfill simulation test set-up, and Figure B-3 is a photograph of the $140^{\circ} \mathrm{F}$ landfill simulation test set-up. 


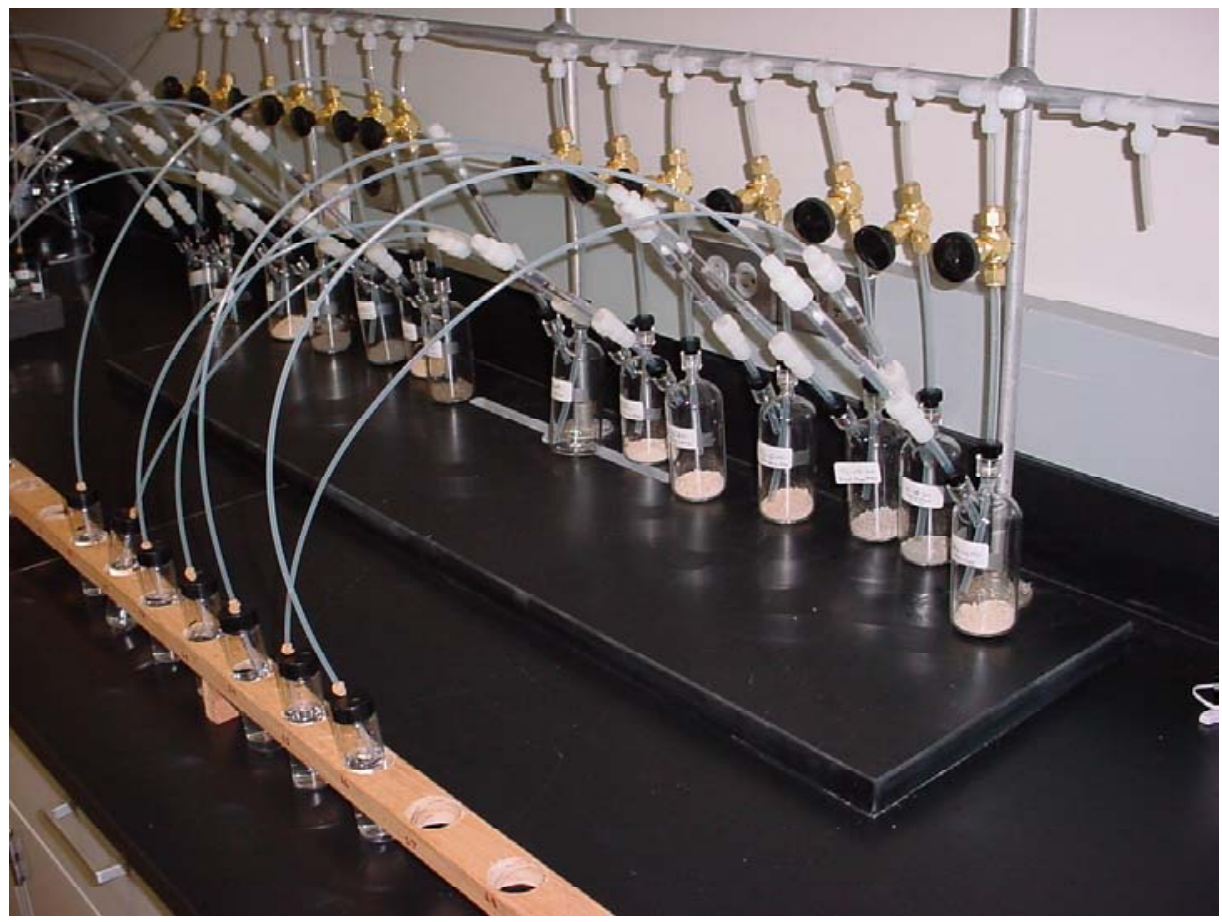

Figure B-2. Photograph of the Room Temperature Landfill Test Set Up.

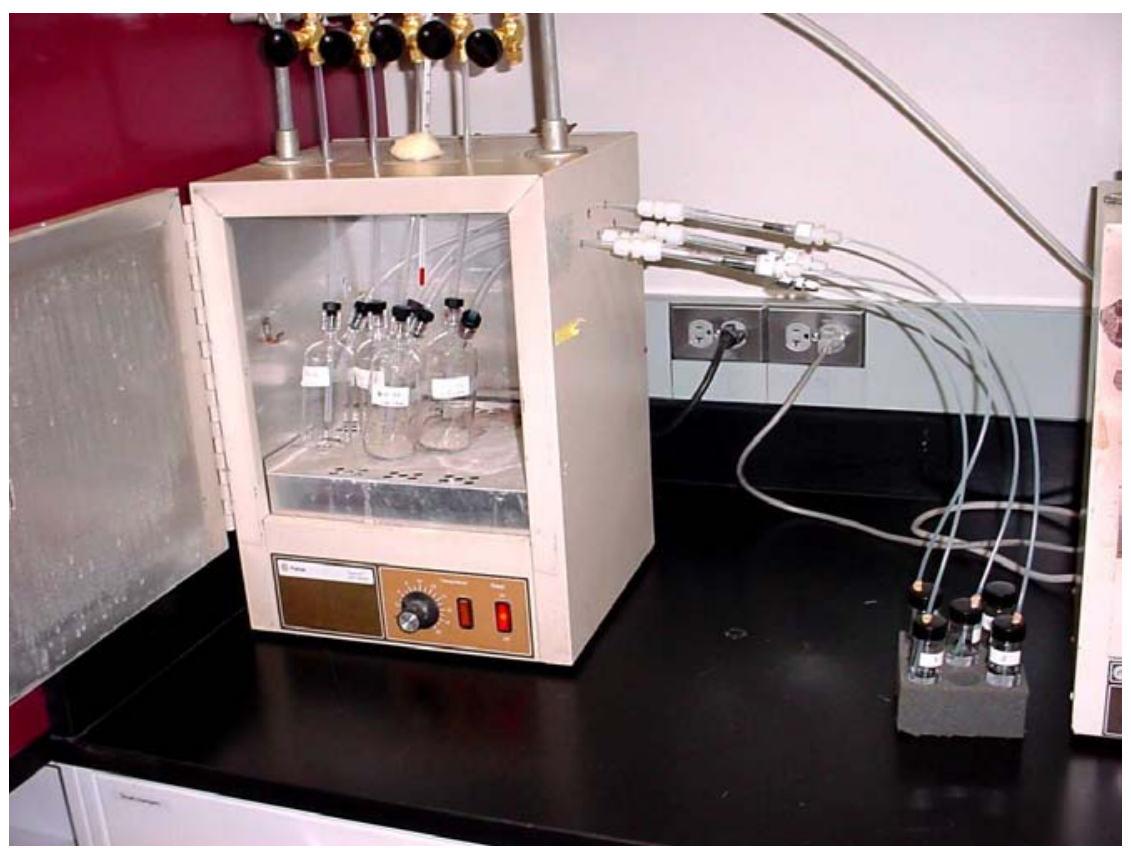

Figure B-3. Photograph of the $140^{\circ}$ F Landfill Test Set Up. 
The landfill simulations were run using a high flow rate of air, which was intended to represent windy ambient conditions. The rate was chosen to be approximately 50 $\mathrm{mL} / \mathrm{min}$. All flow rates were measured with a digital flow meter periodically throughout the tests, and before and after each Carulite change. The flow rate ranged from 45 to 55 $\mathrm{mL} / \mathrm{min}$ throughout the Powerton by-product samples room temperature landfill simulation 8-week test period, and ranged from 44 to $54 \mathrm{~mL} / \mathrm{min}$ throughout the Powerton by-product sample $140^{\circ} \mathrm{F}$ landfill simulation 24 -week test period. The flow rate ranged from 46 to $55 \mathrm{~mL} / \mathrm{min}$ throughout the VAPP by-product sample room temperature landfill simulation 18-week test period, and ranged from 50 to $55 \mathrm{~mL} / \mathrm{min}$ throughout the VAPP by-product sample $140^{\circ} \mathrm{F}$ landfill simulation 18 -week test period.

The ambient temperature in the laboratory was monitored with a digital thermometer that has the capability of recording the maximum and minimum temperature reached over a period of time. These temperatures were recorded periodically throughout the landfill simulation test periods. The average observed temperature for the Powerton by-product sample room temperature simulation tests was $72.9^{\circ} \mathrm{F}$, while the average observed temperature for the VAPP by-product sample room temperature simulation tests was $69.1^{\circ} \mathrm{F}$. The average temperature of the Powerton by-product sample $140^{\circ} \mathrm{F}$ simulation test was $139.8^{\circ} \mathrm{F}$, while the average temperature of the VAPP by-product sample $140^{\circ} \mathrm{F}$ simulation test was $141.6^{\circ} \mathrm{F}$.

Before the landfill simulation tests were started, a portion of each sample was analyzed for mercury. By-product samples containing sorbent were analyzed for mercury using ASTM method D3684 that involved the use of an oxygen Parr Bomb. The baseline ashes were analyzed for mercury by a conventional hydrofluoric acid digestion. Furthermore, due to the limited amount of the Powerton samples, the room temperature landfill simulation tests were run for an 8 -week period rather than a 24 -week period. These samples were recovered and used for the testing described in the next section.

\section{B.1.2 Mercury Desorption Tests}

Desorption tests were performed on the Powerton by-product samples. These tests used cold vapor atomic adsorption (CVAA) to measure the amount of mercury desorbed from the sample as a function of temperature. One gram $(\mathrm{g})$ of solid was combined with $9 \mathrm{~g}$ of acid cleaned sand and placed in a clean glass column. Next, approximately $750 \mathrm{~mL} / \mathrm{min}$ of air was passed through the column while the temperature was raised incrementally until most of the mercury was desorbed. The desorbed mercury was captured on a gold column, and then thermally desorbed and measured by CVAA. The purpose of this test was to determine at what temperatures the mercury would desorb from the by-product sample. This information could give insight into how strongly the mercury is bound to the sorbent. This may indicate whether the by-product sample could be regenerated for

reuse as a mercury sorbent. The tests were started at room temperature and raised quickly to $140^{\circ} \mathrm{F}$. Next, the temperature was raised in the following increments: $250^{\circ} \mathrm{F}, 350^{\circ} \mathrm{F}$, $400^{\circ} \mathrm{F}, 450^{\circ} \mathrm{F}, 500^{\circ} \mathrm{F}, 550^{\circ} \mathrm{F}, 600^{\circ} \mathrm{F}$, and $700^{\circ} \mathrm{F}$. Each temperature was held until mercury desorption was no longer observed. Blank data were also acquired. 


\section{B.1.3 Leaching Test Procedure and Conditions}

All samples were tested using EPA method 1312-Synthetic Precipitation Leaching Procedure (SPLP). As stated by the method, a 1:20 solid to liquid ratio was the criteria used for each sample set. EPA method 1312 was selected under the theory it would simulate the conditions relevant to the type of landfill an ash byproduct would be disposed in. This method simulates "acid rain" using sulfuric acid and nitric acid. The Powerton by-product samples were tested using the SPLP matrix at $\mathrm{pH}$ 's of 2.5 and 5.0, and at a $\mathrm{pH}$ of 7.0 using ASTM type II water. The VAPP by-product samples were tested using the SPLP matrix at a $\mathrm{pH}$ of 4.2 , ASTM type II water $(\mathrm{pH}=7), 0.1 \mathrm{M} \mathrm{Na}_{2} \mathrm{CO}_{3}(\mathrm{pH}=$ $11.42)$, and $0.1 \mathrm{~N} \mathrm{H}_{2} \mathrm{SO}_{4}(\mathrm{pH}=1.30)$. The sorbent/fluid mixtures were rotated at 28 to 32 $\mathrm{rpm}$ in a rotary extractor device for 16 to 20 hours at room temperature. Next, the samples were filtered using acid cleaned glassware and glass fiber filters, and the leachates were analyzed for mercury concentrations using EPA method 7470. The appropriate blanks, duplicates, and spike samples were also tested. Each result was compared to untreated sorbent material. 


\section{Appendix C. Sorbent Information}

\begin{tabular}{|c|c|c|}
\hline Sorbent Vendor & Sorbent Name & Site Evaluated \\
\hline \multirow[t]{2}{*}{ Norit Americas Inc. } & FGD & Powerton, VAPP, and P4 \\
\hline & $2002-8680$ and $2002-8567$ & VAPP \\
\hline \multirow[t]{3}{*}{ Illinois State Geological Survey } & CFA & Powerton, VAPP, and P4 \\
\hline & CS80 & Powerton, VAPP, and P4 \\
\hline & LAC & VAPP and P4 \\
\hline EnviroTire Technologies, Ltd. & TDAC & Powerton, VAPP, and P4 \\
\hline Donau Carbon & HOK & Powerton, VAPP, and P4 \\
\hline \multirow[t]{2}{*}{ Separation Technologies, Inc. } & STI-020513-B, 020930-C, A & VAPP \\
\hline & STI-B & Powerton \\
\hline Barneby Sutcliffe Corp. & IAC and IAC 020430-B & Powerton, VAPP, and P4 \\
\hline ARKAY Technologies, Inc. & S-1 and E-1-S & VAPP \\
\hline Physical Sciences Inc. & PSI-C & VAPP \\
\hline \multirow[t]{2}{*}{ Sorbent Technologies, Inc. } & $\mathrm{A} 10$ and $\mathrm{G}$ & VAPP \\
\hline & A6 and A5 & $\mathrm{P} 4$ \\
\hline CarboChem Inc. & MC-40, MG-20 & $\mathrm{P} 4$ \\
\hline Amended Silicates LLC & AMS & P4 \\
\hline Penn State University & FA1 & $\mathrm{P} 4$ \\
\hline Carbon Resources, LLC & CR325A and CR325D & P4 \\
\hline $\begin{array}{l}\text { United Manufacturing } \\
\text { International }\end{array}$ & UMI-FG9B & $\mathrm{P} 4$ \\
\hline Superior Adsorbents, Inc. & Sample 1 and 2 & P4 \\
\hline DOE/NETL & Thief & $\mathrm{P} 4$ \\
\hline Praxair, Inc. & PRA58 & P4 \\
\hline
\end{tabular}




\section{Appendix D. Laboratory Sorbent Fixed-Bed Evaluations}

Table D-1. Results from Laboratory Fixed-Bed Mercury Adsorption Capacity Tests on Simulated Low Sulfur Eastern Bituminous Flue Gas.

\begin{tabular}{|c|c|c|c|c|}
\hline Vendor & Sample Name & $\begin{array}{c}\text { Temp. } \\
\left({ }^{\circ} \mathrm{F}\right)\end{array}$ & $\begin{array}{c}\mathrm{HgCl}_{2} \text { Equil. Ads. Cap. } \\
\text { at } 50 \mu \mathrm{g} \mathrm{HgCl} / \mathrm{Nm}^{3} \\
(\mu \mathrm{g} / \mathrm{g})\end{array}$ & $\begin{array}{c}\mathrm{Hg}^{\circ} \text { Equil. Ads. Cap. } \\
\text { at } 50 \mu \mathrm{g} \mathrm{Hg}^{\circ} / \mathrm{Nm}^{3} \\
(\mu \mathrm{g} / \mathrm{g})\end{array}$ \\
\hline Advanced Fuel Research & AFR-g & 275 & 1797 & \\
\hline Advanced Fuel Research & AFR-2 & 275 & 961 & \\
\hline Arkay & E-5-CN-02 & 275 & 115 & \\
\hline Arkay & E-4-A-02 & 275 & 1 & \\
\hline Arkay & E-3-CC-02 & 275 & 93 & \\
\hline Carbochem & FGC & 275 & 2303 & \\
\hline Carbochem & IGC & 275 & 1625 & \\
\hline Carbochem & PC-50 & 275 & 261 & \\
\hline Donau & GAL - ISGS & 275 & 1150 & \\
\hline Donau & HOK & 275 & 1750 & \\
\hline Dynamic Catalysts and Adsorbants & Dynasorb-200 & 275 & 0 & \\
\hline Dynamic Catalysts and Adsorbants & Dynasorb-E Cat & 275 & 16 & \\
\hline Norit & FGD & 275 & 1494 & 618 \\
\hline Norit & FGD Fines & 275 & 3475 & 1687 \\
\hline Norit & Hydro Darco & 275 & 2131 & \\
\hline Norit & FGL & 275 & 1901 & 916 \\
\hline Norit & FGD/HCl & 275 & 1239 & - \\
\hline Norit & FGD/Lime & 275 & 1620 & 784 \\
\hline Physical Sciences Inc. & PSI-A & 275 & 1672 & \\
\hline Physical Sciences Inc. & PSI-B & 275 & 4172 & \\
\hline Physical Sciences Inc. & PSI-C & 275 & 4047 & \\
\hline Physical Sciences Inc. & PSI-D & 275 & 2468 & \\
\hline Superior Adsorbants, Inc. & SAI-A & 275 & 520 & \\
\hline Superior Adsorbants, Inc. & SAI-B & 275 & 614 & \\
\hline Sorbent Technologies, Inc. & Sorbtech A & 275 & 2007 & \\
\hline Sorbent Technologies, Inc. & Sorbtech B & 275 & 2417 & \\
\hline Sorbent Technologies, Inc. & Sorbtech C & 275 & 368 & \\
\hline Sorbent Technologies, Inc. & Sorbtech D & 275 & 288 & \\
\hline Sorbent Technologies, Inc. & Sorbtech E & 275 & 311 & \\
\hline Sorbent Technologies, Inc. & Sorbtech F & 275 & 279 & \\
\hline Sorbent Technologies, Inc. & Sorbtech I & 275 & 399 & \\
\hline Sorbent Technologies, Inc. & Sorbtech J & 275 & 615 & \\
\hline Sorbent Technologies, Inc. & Sorbtech K & 275 & 257 & \\
\hline Sorbent Technologies, Inc. & Sorbtech L & 275 & 1719 & \\
\hline ISGS & LAC-0101 & 275 & 2196 & 555 \\
\hline ISGS & Pilot-5 & 325 & 684 & 185 \\
\hline ISGS & CFA-6 & 275 & 1160 & 1288 \\
\hline ISGS & TDAC-00 & 275 & 922 & 444 \\
\hline ISGS & IPAC-5 & 325 & 238 & 94 \\
\hline ISGS & PDAC-Pilot & 325 & 347 & 1129 \\
\hline American Absorbents Natural Products & AANP Zeolite-200 & 325 & - & 30 \\
\hline & NaA Zeolite & 325 & 0 & 0 \\
\hline Comercial Zeolite modified by ISGS & $\mathrm{NaA}-\mathrm{S} 400$ & 325 & 2825 & 25 \\
\hline ISGS & Soot 60 & 275 & 308 & - \\
\hline ISGS & Soot 80 & 275 & 990 & - \\
\hline
\end{tabular}




\section{Appendix D (cont.)}

Table D-2. Results from Laboratory Fixed-Bed Mercury Adsorption Capacity Tests on Simulated PRB Flue Gas.

\begin{tabular}{|c|c|c|c|c|}
\hline Vendor & Sample Name & $\begin{array}{c}\text { Temp. } \\
\left({ }^{\circ} \mathrm{F}\right)\end{array}$ & $\begin{array}{c}\mathrm{Hg}^{\circ} \text { Equil. Ads. Cap. } \\
\text { at } 50 \mu \mathrm{g} \mathrm{HgCl} / \mathrm{Nm}^{3} \\
(\mu \mathrm{g} / \mathrm{g})\end{array}$ & $\begin{array}{c}\mathrm{Hg}^{\circ} \text { Equil. Ads. Cap. } \\
\text { at } 50 \mu \mathrm{g} \mathrm{Hg} / \mathrm{Nm}^{3} \\
(\mu \mathrm{g} / \mathrm{g})\end{array}$ \\
\hline Norit & FGD & 275 & 903 & \\
\hline Advanced Fuel Research & AFR-g & 275 & 314 & \\
\hline Arkay & W-4-A-02 & 275 & 3 & \\
\hline Arkay & W-3-CC-02 & 275 & 5 & \\
\hline Superior Adsorbants, Inc. & SAI-A & 275 & 298 & \\
\hline Superior Adsorbants, Inc. & SAI-B & 275 & 365 & \\
\hline Sorbent Technologies, Inc. & Sorbtech A & 275 & 2148 & \\
\hline Sorbent Technologies, Inc. & Sorbtech B & 275 & 2460 & \\
\hline Sorbent Technologies, Inc. & Sorbtech C & 275 & 232 & \\
\hline Sorbent Technologies, Inc. & Sorbtech D & 275 & 208 & \\
\hline Sorbent Technologies, Inc. & Sorbtech E & 275 & 164 & \\
\hline Sorbent Technologies, Inc. & Sorbtech L & 275 & 2453 & \\
\hline Donau & GAL-ISGS & 275 & 716 & \\
\hline Physical Sciences Inc & PSI-C & 275 & 61 & \\
\hline Norit & FGD & 325 & & 450 \\
\hline ISGS & LAC-0101 & 325 & & 670 \\
\hline ISGS & Pilot-5 & 325 & & 412 \\
\hline ISGS & CFA-6 & 325 & & 847 \\
\hline ISGS & TDAC-00 & 325 & & 227 \\
\hline ISGS & IPAC-5 & 325 & & 84 \\
\hline ISGS & PDAC-Pilot & 325 & & 201 \\
\hline American Absorbents Natural Products & AANP Zeolite-200 & 325 & & 37 \\
\hline & $\mathrm{NaA}$ Zeolite & 325 & & 9 \\
\hline & NaA-S400 & 325 & & 5 \\
\hline ISGS & Soot 60 & 275 & & 264 \\
\hline ISGS & Soot 80 & 275 & & 1313 \\
\hline
\end{tabular}




\section{References}

1. J.H. Pavlish, et al., "Status review of mercury control options for coal-fired power plants", Fuel Processing Technology, 82, 89-165, 2003.

2. T.R. Carey, O.W. Hargrove, C.F. Richardson, "Factors affecting mercury control in utility flue gas using sorbent injection", Proceedings of the Air and Waste Management Association $90^{\text {th }}$ Annual Meeting, Toronto, Ontario, Canada, June 8-13, 1997.

3. R. Chang, G. Offen, Power Engineering, November, 51-57, 1995.

4. "Development and Evaluation of Low-Cost Sorbents for Removal of Mercury Emissions from Coal Combustion Flue Gas," EPRI Report TR-110532, EPRI, Palo Alto, CA, 1998.

5. C.R. Carey, O.W. Hargrove, C.F. Richardson, R. Chang, F.B. Meserole, J. Air \& Waste Management Association, 48, December, 1166-1174, 1998.

6. A. Attar, Fuel, 57, 201-212, 1978.

7. Data from EPA Information Collection Request for Mercury at Electric Utility Steam Generating Units, 1999.

8. "Laboratory Investigations and Model Development of Flue Gas Mercury Adsorption Using Solid Sorbents," EPRI Report TR-110533, EPRI, Palo Alto, CA, 1998.

9. R.D. Vidic, S. Kwon, D.P. Siler, "Impregnated activated carbons for elemental mercury adsorption", Proceedings of the $17^{\text {th }}$ Annual Pittsburgh Coal Conference, , Paper 19a-3, Pittsburgh, PA, September 11-14, 2000.

10. W. Liu, R.D. Vidic, T.D. Brown, "Optimization of sulfur impregnation protocol for fixed-bed application of activated carbon-based sorbents for gas-phase mercury removal”, Environ. Sci. Technol., 32, 531-538, 1998. 